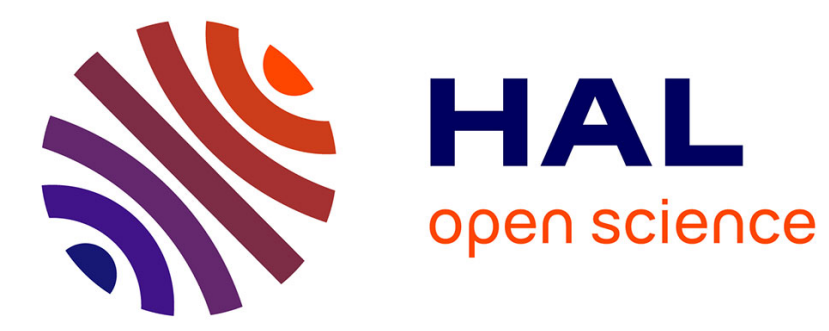

\title{
Heuristic shape optimization of baffled fluid distributor for uniform flow distribution
}

\author{
Lingai Luo, Min Wei, Yilin Fan, Gilles Flamant
}

\section{To cite this version:}

Lingai Luo, Min Wei, Yilin Fan, Gilles Flamant. Heuristic shape optimization of baffled fluid distributor for uniform flow distribution. Chemical Engineering Science, 2015, 123, pp.542-556. 10.1016/j.ces.2014.11.051 . hal-01175587

\section{HAL Id: hal-01175587 \\ https://hal-univ-perp.archives-ouvertes.fr/hal-01175587}

Submitted on 2 Mar 2021

HAL is a multi-disciplinary open access archive for the deposit and dissemination of scientific research documents, whether they are published or not. The documents may come from teaching and research institutions in France or abroad, or from public or private research centers.
L'archive ouverte pluridisciplinaire HAL, est destinée au dépôt et à la diffusion de documents scientifiques de niveau recherche, publiés ou non, émanant des établissements d'enseignement et de recherche français ou étrangers, des laboratoires publics ou privés. 
1 Luo, L., Wei, M., Fan, Y., \& Flamant, G. (2015). Heuristic shape optimization of baffled fluid distributor for uniform flow distribution. Chemical Engineering Science,

\section{Heuristic Shape Optimization of Baffled Fluid Distributor for}

\section{Uniform Flow Distribution}

\section{Abstract}

This paper presents a CFD-based, heuristic evolutionary algorithm for shape design and optimization of baffled fluid distributor. In this algorithm, the baffle surface is firstly divided with numerous identical control areas (volumes), each control area having an orifice in the middle. Under the constraint of constant global porosity of the baffle, the algorithm adjusts the size distribution of orifices so as to approach identical mass flowrate passing through every control area. An automatic program is processed iteratively so that the baffle configuration evolves toward the optimized shape, providing a uniform flow distribution among parallel outlet channels.

\footnotetext{
${ }^{*}$ Corresponding author. Tel.: +33 240683167; Fax: +33 240683141. E-mail address: lingai.luo@univ-nantes.fr
} 
1 To illustrate the principles and procedure of this algorithm, a 2D example of baffled fluid distributor

2 is introduced and tested. Numerical results show that this algorithm can successfully reach uniform

3 flow distribution with a small pressure drop increase. Sensibility analysis also shows that this

4 algorithm is robust, effective, general and flexible compared to traditional arbitrary or empirical

5 propositions. A parametric study of influencing design parameters on the performance of the

6 algorithm is carried out in order to provide some design guidelines. Finally, the theoretical basis and

7 essential steps for the extension of the current algorithm to tackle 3D problem are established. The

8 easy implementation of this simply solution for the general fluid maldistribution problem

9 demonstrates its promising application in real engineering field.

10 Keywords: Flow maldistribution; Perforated baffle; Distributor; Shape optimization; CFD 


\section{1. Introduction}

2 Delivering and distributing precise and controlled flows of one or more fluids into a bundle of parallel

3 channels of multi-tubular equipment is a great challenge for many unit operations of process engineering. Single phase fluid flow maldistribution is an important cause of globally poor performance of heat exchangers, fluidized beds and catalytic monoliths. When mixing of different fluids is involved, such as in chemical reactors, in combustors and in absorption columns, the impact of flow maldistribution might be more disastrous because it may change dramatically the proportion between reactants.

Flow maldistribution can be classified into two categories: gross maldistribution and passage-to-passage maldistribution (Mueller and Chiou, 1988). The latter usually occurs in highly compact devices mainly caused by manufacturing tolerances among passages, fouling, blockage due to condensable impurities, etc. If properly operated, such differences can be less than $5 \%$ (Rebrov et al., 2011). On the other hand, the gross maldistribution is mainly associated with improper design of fluid distributor and/or collector configurations (also referred to as headers or manifolds). The maximum to minimum flowrate ratio among parallel channels, though depending on various factors

16 (eg. inlet velocity, drag coefficient of the distributor, number of parallel channels, etc.), can vary from several tens of percent just up to factors of tens to hundreds (Saber et al., 2009; Tondeur et al., 2011a). Therefore, many studies have been accomplished and attempted on design and optimization of fluid distributor with the purpose of improving the flow distribution uniformity. 
optimize the geometrical parameters of fluid distributor, such as the diffuser angle (eg. Commenge et al., 2002; Jiao et al., 2003a; Tondeur et al., 2011b; Kumaran et al., 2013; Midoux and Tondeur, 2014a, $2014 b$ ), the ratio of distributor area to channel area (Jiao et al., 2003b) and the locations of inlet/outlet tubes (Chein and Chen, 2009; Dang and Teng, 2011). The general idea is to provide sufficient distance between the inlet tube of the distributor and the parallel channels for the development of a regular flow profile. This usually implies that the fluid distributor occupies a large space which is unfavorable regarding volume compactness.

Some researchers also proposed to use nature-inspired tree-like structures as fluid distributing network. Various tree-like (or arborescent) distributors were designed to deliver a certain quantity of fluid from a single inlet to a series of parallel channels evenly spaced on a line (point-to-line problem, Ajmera et al., 2002; Barber and Emerson, 2008; Wang and Wang, 2007; Yue et al., 2010; Liu and Li, 2013; Tarlet et al., 2014), on a surface (point-to-surface problem, Tondeur and Luo, 2004, Fan et al., 2008b; Chen et al., 2010; Tondeur and Menetrieux, 2011; Tesař, 2011; Guo et al., 2013), or to a volume to be drained (point-to-volume problem, Gheorghiu et al., 2005; Tondeur et al., 2009). It is known that multi-scale tree-like distributor could provide better flow distribution uniformity preferentially for laminar flow (Luo et al., 2007; Luo et al., 2008). When the flowrate increases, tree-like distributors become less efficient mainly due to the influence of inertial force. A slight asymmetry velocity profile at one bifurcation would lead to significant maldistribution after successive bifurcations (Fan et al., 2008a). Worse still is the drastic increase of pressure drop due to singular losses in numerous bifurcations, elbows or downcomers in complex tree-like structures (Fan et al., 2008a; Tondeur et al., 2009). Other researchers focused on the multi-scale network based on 
resistance method is presented to calculate the flow characteristics of multi-scale microchannel reactors, under laminar and isothermal conditions.

Another common solution to the flow maldistribution problem is adding "packings" as additional hydraulic resistance inside the distributor. Packings could be either thick wall screens (Rebrov et al., 2007a, 2007b), or thin wall screens like meshes or gauzes. In particular, a thin perforated baffle is widely introduced in the inlet distributor to improve the flow distribution uniformity. Table 1 summarizes various studies in the literature on fluid distributors with insertion of perforated baffle. It is generally reported that the baffled fluid distributor could effectively improve the flow distribution uniformity with an acceptable pressure drop increase. Moreover, they can be easily fabricated and installed with less cost compared to tree-like distributors.

Nevertheless, by exploring in more detail the perforated baffle, we may find out that the configurations proposed could be very different, even arbitrary, as illustrated in Fig. 1. The orifices drilled in the plate could have identical or different diameters (usually small orifices at the centre of baffle and big orifices on the edge), and be arranged in single line or in multiple lines. In any case, the topology of the orifices' distribution, more specifically, the arrangement of the orifices on the plate and their size distribution are either empirical or intuitive. To the best of our knowledge, neither theoretical guidelines nor basic principles were proposed or established for the design and optimization of the baffle configuration. This will result in two consequences since the equidistribution effect of perforated baffle is generally restricted to a certain range of flow circuit geometry (eg. number of parallel channels) and working condition (eg. inlet velocity). Firstly, the best topology configuration of the perforated baffle can not be determined for one specific circuit geometry and 
1 under certain working condition. Secondly, once the circuit geometry or working condition changes,

2 the equidistribution effect would probably be no longer in force. Then trial-and-error tests are

3 inevitable until finding a non-optimal but acceptable new configuration. As a result, the development

4 of a general method for the design and optimization of baffled fluid distributor is of great interests in

5 fields wherever the flow maldistribution problem exists.

6 In this study, a heuristic evolutionary algorithm (Luo et al., 2014) is proposed for the design and

7 shape optimization of baffled fluid distributor for uniform flow distribution. The algorithm is

8 CFD-based, and can be considered as a small extension in the general framework of Cellular

9 Automata (CA) (Wolfram, 2002). With this algorithm, we try to automatically evolve the size and

10 distribution of orifices on the perforated baffle in order to determine the optimal topology

11 configuration subject to each particular case. Compared to traditional arbitrary or empirical

12 propositions, this algorithm is more general, precise and flexible, and can be easily applied to

13 different distributor geometries and different working conditions.

14 We shall first present the heuristic algorithm with a general 2D case, appropriate for introducing basic

15 principles and for describing in detail each step of the algorithm. A numerical benchmark will then be developed and optimization results will be presented. The influences of various design and operational parameters will be analyzed and discussed. The theoretical basis for the extension of the current algorithm to tackle 3D problem are also established. Finally, remarks and main conclusions will be summarized.

Fig. 1. Different baffle configurations proposed in the literature. (a) Adapted from Lalot et al. (1999). (b) Adapted 
from Wang et al. (2011). (f) Adapted from Krichnavaruk and Pavasant (2002). (g) Adapted from Maharaj et al.

Table 1 Selected studies on fluid distributor with insertion of perforated baffle.

\section{2. Heuristic evolutionary algorithm}

5

6

The basic idea of this study is to homogenize the velocity profile in the distributor by the insertion of a perforated baffle instead of natural development, as shown in Fig. 2. The size and distribution of orifices should be arranged in such a way that a regular velocity profile on the whole surface could be achieved at the downstream of the baffle (before the inlets of parallel channels). To do that, we first divide the baffle into numerous small sections, each section having an orifice in the middle. The objective of the algorithm is to obtain identical fluid flux in every section by modulating the size of every orifice. Locally uniform velocity profiles will then merge into a global regular one. We will describe in detail in this section the basic principles and steps of this heuristic algorithm with a 2D example. To simplify the numerical algorithm, we assume steady Newtonian fluid flow in this study.

Fig. 2. Schematic view of the effect of perforated baffle on the homogenization of velocity profile.

\subsection{Introduction of notations}

Fig. 3 shows a representative 2D baffled fluid distributor with single inlet tube (width $w$ ) and certain amount of outlet channels $(M)$ corresponding to the downstream equipment. The total inlet mass flowrate equals to $Q$. A perforated baffle with thickness $(e)$ is installed inside of the distributor. The length of the baffle $(L)$ is equal to the width of the distributor chamber and the location of baffle inside the distributor $(h / H)$ is a parameter subject to study. The baffle with length $L$ is uniformly divided into 
$1 N$ control areas of same length $I$. Each control area $i$ has one orifice of size $d_{i}$ arranged in the middle,

2 and the flowrate passing through is $q_{i}$. Then following relations could be derived based on geometric

3 considerations and mass conservation.

4

5

6

7

8

9 The mean flowrate among orifices $\bar{q}$ can be calculated as:

10

Fig. 3. Representative example of a fluid distributor with insertion of perforated baffle.

$$
\phi=\frac{\sum_{i=1}^{N} d_{i}}{L}=\frac{\sum_{i=1}^{N} \varepsilon_{i}}{N}
$$

where $\varepsilon_{i}$ is the local porosity in the ith control area, $\Phi$ the global porosity of the baffle.

11 Note that the departure of $q_{\mathrm{i}}$ from $\bar{q}$ depends on the location of the ith control area on the baffle and

12 the size of the orifice $d_{i}$.

\subsection{Basic principles}

14 The objective of the evolutionary algorithm is to determine the optimal size distribution of orifices so

15 that the flowrate in every control area is identical. 


$$
\frac{q_{i}}{l}=\frac{q_{j}}{l}=\frac{\bar{q}}{l}
$$

Practically, the diameter of each orifice $d_{i}$ will be modulated by comparing $q_{i}$ and $\bar{q}$, as explained in

Fig. 4. More precisely, if the flowrate in the ith control area $q_{\mathrm{i}}$ is larger than the mean value, then the size of the orifice $d_{i}$ should be reduced (Fig. 4a). Vice versa if $q_{i}$ is smaller than $\bar{q}, d_{i}$ should be enlarged so that it could receive higher amount of fluid flux (Fig. 4b). The variation of different $d_{i}$ according to the difference between $q_{\mathrm{i}}$ and $\bar{q}$ repeats literally until the optimality criterion Eq. (5) is achieved. To realize this evolutionary procedure, a cellular automata based iterative program is developed and will be described in next subsection.

9 Fig. 4. Basic principles of the optimization algorithm. (a) Reduction of the orifice. (b) Enlargement of the orifice. Ideally, the increment or decrement of $d_{i}$ from one optimization step to another should be as small as possible (usually elemental cell length). However, that will by far lengthen the calculation time thus it is not highly efficient. Therefore, we introduce a variation rule as presented in Eq. (6). Precisely from $t$ to $t+1$ step, the variation of $d_{i}$ is proportional to the departure of $q_{i, t}$ from the mean value:

$$
\Delta d_{i, t}=d_{i, t+1}-d_{i, t}=\gamma\left(1-\frac{q_{i, t}}{\bar{q}}\right)
$$
baffle is kept constant during the optimization procedure:

$$
\sum_{i=1}^{N} \Delta d_{i, t}=\gamma \sum_{i=1}^{N}\left(1-\frac{q_{i, t}}{\bar{q}}\right)=\gamma\left(N-\frac{Q}{\bar{q}}\right)=0
$$




$$
\phi_{t+1}=\frac{\sum_{i=1}^{N} d_{i, t+1}}{L}=\frac{\sum_{i=1}^{N} d_{i, t}+\sum_{i=1}^{N} \Delta d_{i, t}}{L}=\phi_{t}
$$

2 We also restrict that the boundary of the control area does not move during optimization (I is constant

3 and uniform) and that the boundary of orifice can not overstep the boundary of control area:

$$
\varepsilon_{i, t}=\frac{d_{i, t}}{l} \leq 1
$$

\subsection{Implementation of optimization procedure}

6 The optimization procedure is described in detail using the flow chart shown in Fig. 5.

1. Definition of the geometry of fluid distributor (width of inlet tube, number of channels, etc.) as well as the general operational conditions such as the ambient temperature, operational pressure, amount of heat exchange, etc.

2. Input the initial data relative to working fluid, such as the nature of fluid, the viscosity, compressibility and density of the fluid (temperature and/or pressure dependent or should also be specified.

3. Definition of the parameters relative to the perforated baffle, such as the location and thickness of baffle, number of control area $N$ and the initial distribution of $d_{i}$.

4. Mesh generation of the whole simulation domain, thus the baffled fluid distributor. 
5. Calculation of the exact flow field at steady state, by solving the Navier-Stokes equations.

2 maldistribution factor MF. field. close.

6. Calculation of the mass flowrate $q_{\mathrm{i}}$ passing through each control area and the mean value of flowrate $\bar{q}$; modification of the baffle configuration by comparing $q_{\mathrm{i}}$ to $\bar{q}$, according to the rule presented in Eq. (6).

7. Regeneration of the mesh for updated simulation domain; recalculation of the exact flow

8. Check the stable tolerance of the algorithm. If the tolerance is satisfied, then the heuristic procedure is terminated. If not, the procedure goes back to Step 4 for recurrence. The result is considered to be stable when the size variation at $t$ step $\Delta d_{i, t}$ is smaller than elemental cell size of the mesh. This also implies that the values of $q_{i, t}$ and $\bar{q}$ are very

9. Exportation of results, including the final configuration of perforated baffle, the flow distribution uniformity among parallel outlet channels and the pressure drop of the baffled distributor.

$$
D_{i}=\frac{f_{i}-\bar{f}}{\bar{f}}
$$

$$
\mathrm{MF}=\sqrt{\frac{1}{M-1} \sum_{i=1}^{M}\left(\frac{f_{i}-\bar{f}}{\bar{f}}\right)^{2}}
$$


1 where $M$ stands for the number of parallel outlet channels. $f_{i}$ is the local mass flow rate in ith outlet

2 channel and $\bar{f}$ is the mean flowrate between parallel outlet channels. Uniform flow distribution is 3 achieved when values of $D_{i}$ and MF approach 0.

$$
\bar{f}=\frac{Q}{M}=\frac{\sum_{i=1}^{M} f_{i}}{M}
$$

\subsection{Calculation of flow field by CFD method}

One important step in the algorithm is the calculation of exact flow field in the baffled fluid distributor. This generally involves solving Navier-Stokes equations by finite volume methods. The equation for conservation of mass or continuity is:

$$
\frac{\partial \rho}{\partial t}+\nabla \cdot(\rho \vec{u})=0
$$

The momentum conservation equation is described by:

$$
\frac{\partial}{\partial t}(\rho \vec{u})+\nabla \cdot(\rho \vec{u} \vec{u})=-\nabla p+\nabla \cdot(\Pi)+\rho \vec{g}+\vec{F}
$$

13 where $\vec{u}$ is the velocity, $p$ is the static pressure, $\rho \vec{g}$ and $\vec{F}$ are the gravitational body force and external body forces, $\Pi$ is the stress tensor which is given by:

$$
\Pi=\mu\left[\left(\nabla \vec{u}+\nabla \vec{u}^{\mathrm{T}}\right)-\frac{2}{3} \nabla \cdot \vec{u} I\right]
$$


The energy equation is: Wang et al., 2010; 2014). Having described the heuristic algorithm developed for uniform flow distribution, its effectiveness and sensibility will be tested with an actual example in the next section.

\section{Simulation and results}

\subsection{Numerical benchmark} considered. Fig. 6 shows the schematic view of the case with main geometrical characteristics indicated. The inlet tube is $10 \mathrm{~mm}(w)$ in width and $40 \mathrm{~mm}$ in length while the distributor chamber is $100 \mathrm{~mm}$ in width $(L)$ and $25 \mathrm{~mm}$ in length $(H)$. Ten parallel outlet channels $(M=10)$ with identical $\mathrm{mm}$ from each other. Note that the inlet tube is located in the middle so that the whole geometry is symmetrical.

where $E$ is the internal energy, $\lambda$ is the thermal conductivity, and $Q_{H}$ includes the heat of chemical reaction, radiation and any other volumetric heat sources.

To predict turbulent flow pattern, additional turbulence models should be employed. It is worth noting that besides the traditional CFD methods, new simulation techniques such as the Lattice Boltzmann Method (LBM) can also be used in this regard for more complex fluid domains (Chen and Doolen, 1998; 
1 In this study, the "sudden expansion configuration" of fluid distributor is selected as example because

2 it is the most compact but most difficult to realize the uniform flow distribution. However, the

3 proposed algorithm is not limited to this configuration but suitable for various geometries such as

4 distributors with $30^{\circ}$ or $45^{\circ}$ diffuser angle. The geometry of distributor may vary from case to case,

5 but the optimization procedure remains the same.

6

Fig. 6. Geometry and dimension of the numerical benchmark (unit: $\mathrm{mm}$ ).

The $5 \mathrm{~mm}$-thickness (e) perforated baffle is inserted at the middle of the distributor chamber $(h / H=0.5)$. The baffle is divided into 10 control areas $(N=10)$, the length $(I)$ of each being $10 \mathrm{~mm}$. The initial diameters of orifices are identical and equal to $2 \mathrm{~mm}\left(d_{i, 0}=d_{j, 0}=2 \mathrm{~mm}\right)$, the global porosity $(\Phi)$ being $20 \%$. Note that the initial diameter distribution can be non-uniform, which will be discussed in later subsections. The distribution of $d_{i}$ evolves along with optimization steps while the global porosity of the baffle is kept constant.

Liquid water is used as working fluid. The operation pressure is set at $101325 \mathrm{~Pa}$. Simulations are performed under steady state, isothermal condition without heat transfer. Gravity effect and viscous heating are neglected for simplification. The physical properties of water used in the computation are constant (density $\rho=998.2 \mathrm{~kg} \cdot \mathrm{m}^{-3}$; viscosity $\mu=1.003 \times 10^{-3} \mathrm{~kg} \cdot \mathrm{m}^{-1} \cdot \mathrm{s}^{-1}$ ).

Structured mesh is generated using software ICEM ${ }^{T M}$ (version 12.1) to build up the geometry model. Note that half of the real object is adopted for the purpose of lessening the computational burden because of the symmetric feature of the simulation domain. Generally, one millimeter is divided into ten segments to create square elemental cells. The influence of mesh density on the optimization results is also tested and will be discussed later. 
$1 \quad$ Navier-Stokes equations are resolved by a commercial code ANSYS FLUENT ${ }^{\mathrm{TM}}$ (version 12.1 .4 ) to

2 calculate the flow field. Standard $k-\varepsilon$ model is used to simulate the turbulent flow. For the

3 pressure-velocity coupling, COUPLED method is used. For discretization, standard method is chosen

4 for pressure and second-order upwind differentiation for momentum. Boundary conditions are set as

5 velocity inlet $\left(1.0 \mathrm{~m} \cdot \mathrm{s}^{-1}\right)$ normal to the inlet boundary. Outlets are set to be static pressure boundary,

6 with pressure value being the same as ambient pressure. Adiabatic wall condition is applied and no

7 slip occurs at the wall. The solution is considered to be converged when (i) the mass flow-rate at each

8 outlet channel and the inlet static pressure are constant from one iteration to the next (less than

$9 \quad 0.5 \%$ variation) and (ii) sums of the normalized residuals for control equations are all less than

$101 \times 10^{-6}$

11 The optimization algorithm is written in MATLAB ${ }^{T M}$. At each optimization step, it takes the computed

12 flow field results from FLUENT ${ }^{\mathrm{TM}}$, performs calculations of the displacement according to the variation

13 rule and updates the coordinates of simulation domain. Then, it passes the data required to ICEM ${ }^{\mathrm{TM}}$

14 to regenerate the mesh for the updated geometry.

\subsection{Optimization results}

Fig. 7a shows the evolution of shape and flow field of different optimization steps at three sections of the distributor. The locations of three sections are under the inlet tube, above the baffle and above the parallel channels. Note that step -1 represents the empty distributor without baffle insertion as a reference case while step 0 stands for the initial configuration of the baffle with identical size of orifices. It can be seen that at step -1 , the fluid tends to go preferentially into the channels that face

21 the inlet tube. The flow distribution among parallel outlet channels is obviously not uniform. The 
insertion of uniformly perforated baffle (step 0) serves as an additional flow resistance (a second header). Thus fluid flow is firstly distributed on the baffle plate before reaching the inlets of parallel channels. The flow distribution is homogenized to some extent, but maldistribution still exists, as indicated by the relative flowrate deviation curves shown on Fig. 7b. When the optimization algorithm proceeds, the size distribution of orifices on the baffle evolves in such a way that the same fluid flowrate passing through each orifice is approached. Finally, it reaches a relative steady-state, i.e. the baffle configuration hardly changes as time step increases. In that case, each outlet channel has almost the equal chance to receive the coming fluid, indicating a relatively homogenized flow distribution.

Fig. 7. Shape and flow field evolution of different optimization steps at three sections (a); Relative flowrate deviation of outlet channels for different optimization steps (b). $N=10 ; M=10 ; \Phi=20 \% ; h / H=0.5 ;$ inlet velocity=1

$$
\mathrm{m} \cdot \mathrm{s}^{-1}
$$

Examining the evolution of diameter distribution of orifices along with optimization time steps (Fig. 8), we observe that the sizes of orifices at the centre (No. $5 ; 6)$ and at the edge $($ No. 1,10$)$ of the baffle decrease while those at intermediate zone (No. 2-4; 7-9) increase. This observation differs from the conventional proposition of a monotonously increasing size distribution from centre to the edge of the baffle (eg. Jiao et al., 2003a; Wen and Li, 2004). In fact, the size reduction of central orifices is logical since fluid should be guided toward the edge. As to the size reduction of peripheral orifices, it is a bit counterintuitive owing to the backflow from the distributor walls (boundary effect). Anyway, the optimal configuration of baffle is closely related to the geometry of fluid distributor. 
Fig. 9 shows the evolution of flow maldistribution among parallel outlet channels as a function of optimization time steps. It can be observed that the value of maldistribution factor MF reduces from (optimized configuration). Although only several optimization steps are executed ( 7 steps for this case, little change of flow distribution after the $4^{\text {th }}$ step), the improvement of flow distribution uniformity (optimized with respect to the initial configuration) is significant.

Fig. 9. Maldistribution factor (MF) and pressure drop $(\Delta p)$ as a function of optimization steps. $N=10 ; M=10$;

The improved flow distribution uniformity is along with the increased pressure drop, as shown also in Fig. 9. The value of pressure drop increases from $467 \mathrm{~Pa}$ (empty) to $676 \mathrm{~Pa}$ (initial configuration), and finally reaches $730 \mathrm{~Pa}$ (optimized configuration). It can be observed that $79.5 \%$ of pressure drop increase is caused by installing the baffle (step -1 to step 0 ). The pressure drop increase caused by the optimization process is relatively small $(20.5 \%)$. The heuristic algorithm realizes the optimal allocation of pressure drop, which is the driving force to achieve flow equidistribution.

\subsection{Sensibility analysis}

Having presented the efficiency of proposed heuristic algorithm for uniform flow distribution, the robustness of the algorithm regarding different influencing factors is now examined. order to investigate the sensibility of the algorithm to the choice of initial configuration, a comparative 
test is carried out. This time a non-uniform size distribution of orifices is provided as initial configuration of perforated baffle. All the boundary conditions and physical properties for fluid flow are kept the same. It can be observed from Fig. 10 that by executing the optimization algorithm, different initial configurations lead to a definite and unique optimized configuration. This justifies the robustness of the proposed algorithm to the choice of the initial shape.

Fig. 10. Evolution of size distribution for different initial shapes.

Since in our algorithm the minimum size variation is defined as one cell of mesh, it is necessary to assess the sensibility of the optimized results relative to mesh density. A comparative test regarding the "resolution" of the simulated domain has been carried out. We have refined the mesh (20 segments instead of 10 for $1 \mathrm{~mm}$ ) for the above distributor case, while keeping other numerical parameters unchanged. Results on the improvement of flow distribution uniformity are presented in Fig. 11. It may be observed that the flow distribution uniformity may be further improved when the mesh density increases. This may be attributed to two reasons. On one hand, the calculation of flow field is usually more accurate when more mesh nodes are available. On the other hand, the size variation of orifices could be more precise with a smaller size of elemental cell. However, this further improvement is at the cost of much longer computational time, since more computational time will be consumed to calculate the flow field at each optimization step. For practical applications of the algorithm in real engineering, the mesh density could be determined considering the fabrication precisions and tolerance of maldistribution.

A "progressive refinement technique" may be considered to further improve the efficiency of our algorithm. That is to use firstly coarse mesh and then progressively refine the flow domain in order to 
reach the necessary density. This will be the subject of our future work.

Fig. 11. Influence of mesh density on the performance of optimization algorithm.

\section{4. Effect of design parameters}

4 In this section, the effects of design and operational parameters on the efficiency of the proposed heuristic algorithm will be systematically evaluated. These parameters include the total inlet flowrate

$6(Q)$, the baffle location $(h / H)$, the number of outlet tubes $(M)$ and the global porosity $(\Phi)$.

\subsection{Total inlet flowrate}

Total inlet flowrate of a fluid distributor is one of the key operational parameters which is associated

9 with the throughput or capacity of processes. Meanwhile, it is also an influencing factor for flow maldistribution since it is closed related to the flow patterns (laminar, transitional or turbulent) and velocity profiles in the distributor., A parametric study is carried out by varying the inlet velocity from $0.1 \mathrm{~m} \cdot \mathrm{s}^{-1}$ to $2.0 \mathrm{~m} \cdot \mathrm{s}^{-1}$ in order to test the efficiency of our optimization algorithm within a wide range of inlet flow rate. The corresponding Re number at inlet tube varies from 1000 to 20000 while the mean Re number at outlet channel changes from 100 to 2000.

Fig. 12a shows the evolution of flow distribution uniformity as a function of optimization time steps for different values of inlet velocity. It can be easily observed that flow maldistribution augments with increasing inlet velocity when no baffle is inserted in the distributor (step -1). This is mainly due to the stronger inertial force at higher velocity so that the fluid enters the central outlet channels more preferentially. The insertion of a uniformly perforated baffle (step 0) can reduce the maldistribution to some extent, indicated by the reduction of maldistribution factor MF from 0.128 to 0.044 for $0.1 \mathrm{~m} \cdot \mathrm{s}^{-1}$ 
1 inlet velocity and from 0.324 to 0.189 for $2.0 \mathrm{~m} \cdot \mathrm{s}^{-1}$ inlet velocity. However, it is clear that the initial configuration of baffle is not efficient enough to achieve uniform flow distribution under high inlet flowrate conditions.

By applying the heuristic algorithm, the flow maldistribution can be further reduced. For the optimized configurations, the MF value is 0.012 for $0.1 \mathrm{~m} \cdot \mathrm{s}^{-1}$ inlet velocity and 0.096 for $2.0 \mathrm{~m} \cdot \mathrm{s}^{-1}$ inlet velocity. The improvement of distribution uniformity is always significant with respect to the initial configuration.

Fig. 12. Influence of inlet flowrate on the performance of optimization algorithm. $N=10 ; M=10 ; \Phi=20 \% ; h / H=0.5$

10 It should also be noted that the absolute distribution uniformity of the optimized configuration

11 decreases when total flowrate increases. This is mainly due to the higher inertial forces and locally irregular and chaotic turbulences. Higher mesh density and more subtle size variation rule may be useful to achieve a more uniform flow distribution under high flowrate conditions.

Fig. $12 \mathrm{~b}$ shows the velocity of actual flow fields under $0.5 \mathrm{~m} \cdot \mathrm{s}^{-1}$ inlet velocity at three sections of the distributor. The flow fields are changed when the flow passes the perforated baffle. Five uniform peaks correspond to five channels which make identical flow flux in each channel.

Fig. 13 shows that the total pressure drop in the distributor increases along with the increase of the inlet velocity and higher pressure drop is inevitable to improve the distribution uniformity. As mentioned above, the main pressure drop increase is caused by installing the baffle (Step - 1 to Step $0)$, and the proportion caused by the optimization procedure is relatively small. 
Fig. 13. Influence of inlet flowrate on the pressure drop in the baffled fluid distributor. $N=10 ; M=10 ; \Phi=20 \%$;

$h / H=0.5$.

3

4

5

6

7

\subsection{Location of the baffle}

It is reported that location of the perforated baffle in the distributor chamber may influence the flow distribution uniformity and the best location suggested is in the midway (Lalot et al., 1999). To verify this influence, we have tested two additional cases with the baffle located at the upper-middle $(h / H=0.25)$ or at the bottom-middle $(h / H=0.75)$ of the distributor chamber, to compare with the midway case. Other numerical parameters are kept the same as the benchmark.

Fig. 14 shows the optimized flow distribution among parallel outlet channels for three different baffle locations. It can be observed that the upper-middle case provides the most uniform optimized distribution with maximum flowrate deviation $D_{i}$ less than 0.085 . The optimized distribution of bottom-middle case is relatively the least uniform, the maximum $D_{i}$ being 0.180 . This implies that under the circumstances of our example, longer distance between the baffle and parallel outlet channels is beneficial for the remixing and redevelopment of flow profile at the downstream of the perforated baffle. However, the shorter the distance between the inlet tube and the baffle, the higher pressure drop will be generated, as shown in Fig. 15. The value of total pressure drop at optimized configuration is $590.97 \mathrm{~Pa}, 730.46 \mathrm{~Pa}$ and $1213.57 \mathrm{~Pa}$ for the bottom-middle, midway and upper-middle case, respectively. As a result, the best baffle location should be determined by a trade-off between flow distribution uniformity and pressure drop increase.

Fig. 14. Relative flowrate deviation for optimized configurations with different baffle locations. $N=10 ; M=10$; $\Phi=20 \%$; inlet velocity $=1 \mathrm{~m} \cdot \mathrm{s}^{-1}$. 
Fig. 15. Pressure drop as a function of optimization step, for different baffle locations. $N=10 ; M=10 ; \Phi=20 \%$;

The number of parallel outlet channels has certainly a great impact on the flow maldsitribution, since it is by far more difficult to evenly divide one stream into dozens of small streams than into two or three sub-streams. In order to test the efficiency of the heuristic algorithm within a wide range of number of outlet channels $(M)$, we studies two extra cases with $M$ being 5 or 20 . Other numerical parameters are kept the same as the benchmark except that the distance between two neighboring outlet channels is adjusted accordingly.

Fig. 16 shows the evolution of flow distribution uniformity as a function of optimization time steps for different numbers of outlet channels. It can be observed that the larger the number of outlet channels, the poorer the flow distribution uniformity will be. The value of maldistribution factor (MF) for the empty distributor augments from 0.153 to 0.736 when $M$ increases from 5 to 20 . It is worth noting that the optimized configuration obtained by the heuristic algorithm can always maintain the flow maldistribution at a relatively low level, especially when the number of channels is large. It can also be observed that the optimized distribution becomes relatively less uniform when $M$ increases.

Fig. 16. Influence of number of outlet channels on the distribution uniformity. $N=10 ; \Phi=20 \% ; h / H=0.5 ;$ inlet

$$
\text { velocity }=1 \mathrm{~m} \cdot \mathrm{s}^{-1} \text {. }
$$

19 A factor defined as the ratio of number of control areas to the number of outlet channels $(N / M)$ is 20 introduced to explain these observations. Theoretically speaking, the insertion of perforated baffle 
changes the "topological connectedness" from $1-M$ to $1-N-M$. The heuristic optimization algorithm could guarantee an equidistribution for the stage $1-N$. For the stage $N-M$, it can be roughly analogized as $N$ empty distributors with topological connectedness of $1-M / N$. The distribution uniformity in this stage thus depends on the value of $M / N$. Specifically for the three cases tested, the distribution uniformity is significantly improved compared to the reference case (1-M). Examining in more detail the topological connectedness for each case, as schematically illustrated in Fig. 17, we notice that it corresponds to $1-2$ (bifurcation, $M=20$ ), $1-1$ (straight, $M=10$ ) and 2-1 (merging, $M=5$ ) with internal flow remixing, respectively. It will be easier to achieve equidistribution when fewer sub-streams should be formed. Further discussion could be found in next subsection.

Fig. 17. Schematic view of the topological connectedness between the number of orifices and the number of parallel outlet channels.

\subsection{Global porosity $\Phi$}

A series of comparative tests were performed to study the effect of global porosity $\Phi$ on the performance of the optimization algorithm. The control parameters for different cases are listed in Table 2 . It can be noticed that the tested global porosity $(\Phi)$ ranges from $10 \%, 20 \%$ to $40 \%$. Higher values of porosity may not be accepted since it may violate the constraint of Eq. (9) during the evolution procedure (the boundary of the orifice may overstep the boundary of the control area). For each value of global porosity, different numbers of control areas $(N=10,20,40,50)$ with corresponding initial size of orifices are tested. Other parameters are kept identical, i.e. $M=10$, $h / H=0.5$, inlet velocity at $1 \mathrm{~m} \cdot \mathrm{s}^{-1}$. 
1 Fig. 18. Influences of global porosity and number of orifices on the optimized flow distribution uniformity. $M=10$;

Fig. 19. Influences of global porosity and number of orifices on the pressure drop increase. $M=10 ; h / H=0.5 ;$ inlet

$$
\text { velocity }=1 \mathrm{~m} \cdot \mathrm{s}^{-1} \text {. }
$$

Fig. 18 presents the values of MF for optimized configurations of tested different cases. For a given value of global porosity, larger number of orifices $(N)$ is favorable for more uniform flow distribution. This is coherent to the issue of "topological connectedness" discussed earlier. It seems that when the number of orifices is large, the optimal distribution uniformity that can be achieved for different porosities is very close. However, it should be noted that the absolute values of MF for these cases are so small (less than 0.01 ) that they might be easily influenced by calculation errors or by the mesh

11 flaw.

Examining the pressure drop of the distributor for different cases as shown in Fig. 19, one may observe that the increase of pressure drop due to the insertion of perforated baffle is inversely related

14 to the global porosity of the baffle. The higher the global porosity, the smaller the pressure drop increase will be caused. This analysis indicates that higher global porosity with larger number of orifices (while always keeping local porosity below 1 ) is beneficial to achieve both uniform flow distribution and minimal pressure drop increase.

\section{Extension to 3D}

This problem will be addressed briefly in order to indicate how it can be handled, but without going into details. In fact, the extension of current 2D algorithm to 3D geometry is astonishingly simple and 
1 requires practically no rewriting. Let us merely illustrate the general cases of this point-to-surface problem: a bundle of parallel channels evenly distributed on a rectangular or an oval surface to be irrigated. Uniform flow distribution is required by a proper design of baffled fluid distributor, whose inlet tube is located facing the centre of the surface.

The most delicate part of the exercise is actually to divide the surface (rectangular or oval) by control volumes (instead of control areas for 2D cases), as shown in Fig. 20. Equations (1-3) can then be easily rewritten by replacing linear parameters with surface parameters.

$$
s=\frac{S}{N}
$$

$$
\varepsilon_{i}=\frac{a_{i}}{s}
$$

$$
\phi=\frac{\sum_{i=1}^{N} a_{i}}{S}=\frac{\sum_{i=1}^{N} \varepsilon_{i}}{N}
$$

where $S$ is the surface area of the baffle, $s$ the surface area of the control volume and $a_{i}$ the size of the orifice in ith control volume. The basic principles of the optimization algorithm and evolution rules for the 3D case are:

$$
\begin{gathered}
\frac{q_{i}}{s}=\frac{q_{j}}{s}=\frac{\bar{q}}{s} \\
\Delta a_{i, t}=a_{i, t+1}-a_{i, t}=\gamma\left(1-\frac{q_{i, t}}{\bar{q}}\right)
\end{gathered}
$$
It can be easily verified that the global porosity does not change along with the optimization steps.

17 Implementing the same optimization procedure as for 2D cases, uniform flow distribution may be 
expected using our heuristic algorithm. Of course, more computational time is also needed for the calculation of flow field at each optimization step by CFD code.

3

Note that the shape of control volumes may be rectangular, regular hexagon or those may uniformly pave the entire baffle surface. As to the orifices, the simplest shape is circular or square since the area variation at each optimization step can be realized by modulating single variable (diameter or side length). Of course, other shapes are also realizable regarding different geometries, with the constraint that the boundary of orifice does not overstep the boundary of the control volume during optimization.

Fig. 20. Division of a baffle surface by numerous control volumes for 3D application.

\section{Discussion}

In the current algorithm, uniform and identical value of pressure is assigned as boundary condition for outlet channels. This approximation is appropriate for the shape optimization of inlet fluid distributor as an individual device. However, in compact systems where inlet distributor, parallel channels for unit process operation and outlet collector are highly integrated and closely connected, the configuration of the downstream collector may have a noticeable impact on the upstream flow distribution uniformity between parallel channels. In this case, the algorithm should be modified so that the simulation domain covers the entire geometry from the single inlet to the single outlet. The optimization rule should be updated accordingly as well.

Basic constraints for the proposed algorithm are that the control areas (volumes) are evenly divided and that the boundary of orifices can not overstep the boundary of control areas during optimization 
1 steps (local porosity less than 1 ). These constraints are useful and necessary to guarantee a uniform flow distribution among parallel channels evenly spaced between one another on a line or on a surface. However, when non-uniform but controlled flow distribution is required or unevenly spaced parallel channels are involved in certain operational equipment, these constraints should be modified accordingly. In that case, an additional degree of freedom may be added, i.e. the lengths of control area $l_{i}$ (surface areas $a_{i}$ for $3 D$ application) can be locally varied $\left(l_{i} \neq l_{j} ; l_{i, t} \neq l_{i, t+1}\right)$ corresponding to specified optimization criterion, while keeping the global porosity constant during optimization.

The baffle configuration optimization with our algorithm will surely cause a certain increase of pressure drop in the distributor. However, this pressure drop increase which depends on the configuration of baffle could be relatively small (higher porosity; smaller thickness but within the limit of mechanical deformation). Moreover, this increase can be compensated by the reduced pressure drop of downstream equipment owing to more uniform flow distribution.

It should be noted that the efficiency of the heuristic algorithm depends largely on the precision of the transport phenomena simulation. The more realistic the simulated flow, the more satisfactory results may be achieved. When more complex flows such as varied fluid composition or more complicated situations such as fouling or channel blockage are involved, the selection of adaptive and reliable numerical models is very important. However, the heuristic algorithm is somewhat independent to the CFD codes used.

\section{Conclusion and prospects}

This paper presents a CFD-based, heuristic evolutionary algorithm for shape design and optimization of baffled fluid distributor. In this algorithm, the baffle surface is firstly divided with numerous 
1 identical control areas (volumes), each control area having an orifice in the middle. Under the constraint of constant global porosity of the baffle, the algorithm adjusts the size distribution of orifices so as to approach identical mass flowrate passing through every control area. An automatic program is processed iteratively so that the baffle configuration evolves toward the optimized shape, providing a uniform flow distribution among parallel outlet channels.

Compared to traditional arbitrary or empirical propositions, the advantages of our optimization algorithm lie in two main aspects. On the one hand, it leads to an optimal baffle configuration for a given distributor geometry under certain working condition. On the other hand, it may be easily applied to different flow circuit geometries (eg. different numbers of outlet channels) and different working conditions (eg. different total flowrate). In this sense, this algorithm is robust, effective,

11 general and flexible.

The examples presented in this study deal with single phase flow. The extension of the proposed algorithm for multi-phase flow maldistribution problem is interesting but challenging. This is one direction of our future work and some guidelines may be followed based on the recent works of Schouten's group (Al-Rawashdeh et al., 2012a, 2012b, 2012c, 2014).

It should be noted that higher global performances of devices (in terms of higher thermal efficiency, presence of less hot spots, enhanced mixing, controlled reaction, etc.) for different applications may need different optimal criterion (Mies et al., 2007; Al-Rawashdeh et al., 2013). The development a pertinent performance criterion for special unit operation, and the experimental validation of the optimization algorithm for an actual application are the directions of our ongoing work. 


\section{Acknowledgement}

2 This work is partially financed by the French CNRS within the project AAP-Energie 2012 of INSIS. One

3 of the authors M. Min WEI would like to thank the "Région Pays de la Loire" for its partial financial

4 support to his PhD study. 


\section{$1 \quad$ Notations}

a

d

D

e

E

$f$

$\bar{f}$

F

$g$

$h \quad$ length between inlet and baffle

H length of distributor

I unit tensor

$L$

M

MF

$N$

$p$

$q$

$\bar{q}$

size of the orifice in $3 D$ $\mathrm{m}^{2}$

m

m

$\mathrm{J} \mathrm{kg}^{-1}$

$\mathrm{kg} \mathrm{s}^{-1}$

$\mathrm{kg} \mathrm{s}^{-1}$

$\mathrm{kg} \mathrm{m} \mathrm{s}{ }^{-2}$

$\mathrm{m} \mathrm{s}^{-2}$

$\mathrm{m}$

$\mathrm{m}$

$\mathrm{m}$

$\mathrm{m}$

$\mathrm{Pa}$

$\mathrm{kg} \mathrm{s}^{-1}$

$\mathrm{kg} \mathrm{s}^{-1}$ 
$Q_{H} \quad$ external heat transfer flux

time step

$T$

temperature

K

$u \quad$ velocity

$\mathrm{m} \mathrm{s}^{-1}$

w

width of inlet tube

$\mathrm{m}$

Greek symbols

$\begin{array}{ll}\gamma & \text { relaxation factor } \\ \varepsilon & \text { local porosity } \\ \lambda & \text { thermal conductivity } \\ \mu & \text { viscosity } \\ \prod & \text { stress tensor } \\ \rho & \text { density } \\ \Phi & \text { global porosity }\end{array}$

$\mathrm{W} \mathrm{m} \mathrm{m}^{-1} \mathrm{~K}^{-1}$

$\mathrm{kg} \mathrm{m}^{-1} \mathrm{~s}^{-1}$

$\mathrm{kg} \mathrm{m}^{-3}$

3

Subscripts

$i, j \quad$ orifice and channel index 
Ajmera, S.K., Delattre, C., Schmidt, M.A., Jensen, K.F., 2002. Microfabricated differential reactor for heterogeneous gas phase catalyst testing. Journal of catalysis 209(2), 401-412. Design criteria for a barrier-based gas-liquid flow distributor for parallel microchannels. Chemical Engineering Journal 181-182, 549-556. Al-Rawashdeh, M., Nijhuis, X., Rebrov, E.V., Hessel, V., Schouten, J.C., 2012b. Design methodology for barrier-based two phase flow distributor. AIChE Journal 58(11), 3482-3493.

9 Al-Rawashdeh, M., Yu, F., Nijhuis, T.A., Rebrov, E.V., Hessel, V., Schouten, J.C., 2012c. Numbered-up 10 gas-liquid micro/millichannels reactor with modular flow distributor. Chemical Engineering Journal $11 \quad 207-208,645-655$ Al-Rawashdeh, M., Yu, F., Patil, N.G., Nijhuis, T.A., Hessel, V., Schouten, J.C., Rebrov, E.V., 13 2014.Designing flow and temperature uniformities in parallel microchannels reactor.AIChE Journal 60(5), 1941-1952.

Al-Rawashdeh, M., Zalucky, J., Muller, C., Nijhuis, T.A., Hessel, V., Schouten, J.C., 16 2013.Phenylacetylene hydrogenation over $[\mathrm{Rh}(\mathrm{NBD})(\mathrm{PPh} 3) 2] \mathrm{BF} 4$ Catalyst in a numbered-up 17 microchannels reactor. Industria\& Engineering Chemistry Research 52(33), 11516-11526. principles. Microfluidics and Nanofluidics 4(3), 179-191. 
1 Chein, R., Chen, J., 2009. Numerical study of the inlet/outlet arrangement effect on microchannel heat sink performance. International Journal of Thermal Sciences 48(8), 1627-1638.

Chen, S., Doolen, G.D., 1998. Lattice Boltzmann method for fluid flows. Annual review of fluid mechanics 30(1), 329-364.

Chen, Y., Zhang, C., Shi, M., Yang, Y., 2010. Thermal and hydrodynamic characteristics of constructal tree - shaped minichannel heat sink. AIChE Journal 56(8), 2018-2029.

Commenge, J., Falk, L., Corriou, J., Matlosz, M., 2002. Optimal design for flow uniformity in microchannel reactors. AIChE Journal 48(2), 345-358.

Commenge, J., Saber, M., Falk, L., 2011. Methodology for multi-scale design of isothermal laminar flow networks. Chemical Engineering Journal 173(2), 541-551.

Dang, T., Teng, J.-T., 2011. Comparisons of the heat transfer and pressure drop of the microchannel and minichannel heat exchangers. Heat and mass transfer 47(10), 1311-1322.

Fan, Y., Boichot, R., Goldin, T., Luo, L., 2008a. Flow distribution property of the constructal distributor and heat transfer intensification in a mini heat exchanger. AIChE Journal 54(11), 2796-2808.

Fan, Z., Zhou, X., Luo, L., Yuan, W., 2008b. Experimental investigation of the flow distribution of a 2-dimensional constructal distributor. Experimental Thermal and Fluid Science 33(1), 77-83.

Gheorghiu, S., Kjelstrup, S., Pfeifer, P., Coppens, M.-O., 2005. Is the lung an optimal gas exchanger? Fractals in biology and medicine. Springer.

Guo, X., Fan, Y., Luo, L., 2013. Mixing performance assessment of a multi-channel mini heat 
exchanger reactor with arborescent distributor and collector. Chemical Engineering Journal 227, 116-127.

3 maldistribution in plate-fin heat exchanger. Applied thermal engineering 23(10), 1235-1246. perforated plates. Chemical Engineering Journal 89(1), 203-211.

Kumaran, R.M., Kumaraguruparan, G., Sornakumar, T., 2013. Experimental and numerical studies of header design and inlet/outlet configurations on flow mal-distribution in parallel micro-channels. Applied Thermal Engineering 58, 205-216.

Lalot, S., Florent, P., Lang, S., Bergles, A., 1999. Flow maldistribution in heat exchangers. Applied thermal engineering 19(8), 847-863.

Idelchik I.E., 1991. Fluid Dynamics of Industrial Equipment: Flow distribution design methods. Hemisphere.

Jiao, A., Li, Y., Chen, C., Zhang, R., 2003a. Experimental investigation on fluid flow maldistribution in plate-fin heat exchangers. Heat Transfer Engineering 24(4), 25-31.

Jiao, A., Zhang, R., Jeong, S.K., 2003b. Experimental investigation of header configuration on flow Krichnavaruk, S., Pavasant, P., 2002. Analysis of gas-liquid mass transfer in an airlift contactor with

thermal engineering 19(8), 847-863.

Liu, H., Li, P., 2013. Maintaining equal operating conditions for all cells in a fuel cell stack using an external flow distributor. International Journal of Hydrogen Energy 38(9), 3757-3766.

Luo, L., Fan, Y., Wei, M., Flamant, G., 2014. Procédé de détermination de caractéristiques d'orifices à ménager à travers une plaque et programme correspondant, Brevet français (French Patent) 
Luo, L., Fan, Y., Zhang, W., Yuan, X., Midoux, N., 2007. Integration of constructal distributors to a mini crossflow heat exchanger and their assembly configuration optimization. Chemical engineering science 62(13), 3605-3619. Luo, L., Fan, Z., Le Gall, H., Zhou, X., Yuan, W., 2008. Experimental study of constructal distributor for

6 flow equidistribution in a mini crossflow heat exchanger (MCHE). Chemical Engineering and Processing: Process Intensification 47(2), 229-236.

8 Maharaj, L., Pocock, J., Loveday, B., 2007. The effect of distributor configuration on the 9 hydrodynamics of the teetered bed separator. Minerals Engineering 20(11), 1089-1098.

10 Manikanda Kumaran, R., Kumaraguruparan, G., Sornakumar, T., 2013. Experimental and Numerical 11 Studies of Header Design and Inlet/Outlet Configurations on Flow Mal-distribution in Parallel Micro-channels. Applied Thermal Engineering 58(1-2), 205-216.

13 Midoux, N., Tondeur, D., 2014. The theory of parallel channels manifolds (Ladder networks) revisited 14 part 1: Discrete mesoscopic modelling. The Canadian Journal of Chemical Engineering 92(10), $15 \quad 1798-1821$.

16 Midoux, N., Tondeur, D., 2014. The theory of parallel channels manifolds (Ladder networks) revisited 17 part 2. The Canadian Journal of Chemical Engineering, in press.

18 Mies, M.J.M., Rebrov, E.V., Deutz, L., Kleijn, C.R., De Croon, M.H.J.M., Schouten, J.C., 2007. Experimental validation of the performance of a microreactor for the high-throughput screening of 
Mueller, A., Chiou, J., 1988. Review of various types of flow maldistribution in heat exchangers. Heat Transfer Engineering 9(2), 36-50.

Ong, B., Gupta, P., Youssef, A., Al-Dahhan, M., Dudukovic, M., 2009. Computed tomographic investigation of the influence of gas sparger design on gas holdup distribution in a bubble column. Industrial \& Engineering Chemistry Research 48(1), 58-68.

Rebrov, E.V., Ekatpure, R.P., De Croon, M.H.J.M., Schouten, J.C., 2007a. Design of a thick-walled screen for flow equalization in microstructured reactors. Journal of Micromechanics and

9 Microengineering 17(3), 633-641.

Rebrov, E.V., Ismagilov, I.Z., Ekatpure, R.P., De Croon, M.H.J.M., Schouten, J.C., 2007b. Header design for flow equalization in microstructured reactors. AIChE Journal 53(1), 28-38.

Rebrov, E.V., Schouten, J.C., De Croon, M.H.J.M., 2011. Single-phase fluid flow distribution and heat transfer in microstructured reactors. Chemical Engineering Science 66(7), 1374-1393.

Saber, M., Commenge, J.-M., Falk, L., 2009. Rapid design of channel multi-scale networks with minimum flow maldistribution. Chemical Engineering and Processing: Process Intensification 48(3), 723-733.

17 Saber, M., Commenge, J., Falk, L., 2010. Microreactor numbering-up in multi-scale networks for industrial-scale applications: Impact of flow maldistribution on the reactor performances. Chemical 
1 Sheik Ismail, L., Ranganayakulu, C., Shah, R.K., 2009. Numerical study of flow patterns of compact plate-fin heat exchangers and generation of design data for offset and wavy fins. International journal of heat and mass transfer 52(17), 3972-3983. Tarlet, D., Fan, Y., Roux, S., Luo, L., 2014. Entropy generation analysis of a mini heat exchanger for heat transfer intensification. Experimental Thermal and Fluid Science 53, 119-126. Tesař, V., 2011. Bifurcating channels supplying "numbered-up" microreactors. Chemical Engineering Research and Design 89(12), 2507-2520. Tondeur, D., Fan, Y., Commenge, J.-M., Luo, L., 2011a. Flow and pressure distribution in linear discrete "ladder-type" fluidic circuits: An analytical approach. Chemical Engineering Science 66(12), 2568-2586.

Tondeur, D., Fan, Y., Commenge, J.-M., Luo, L., 2011b. Uniform flows in rectangular lattice networks. Chemical Engineering Science 66(21), 5301-5312. Tondeur, D., Fan, Y., Luo, L., 2009. Constructal optimization of arborescent structures with flow singularities. Chemical Engineering Science 64(18), 3968-3982. Tondeur, D., Luo, L., 2004. Design and scaling laws of ramified fluid distributors by the constructal approach. Chemical Engineering Science 59(8), 1799-1813.

17 Tondeur, D., Menetrieux, C., 2011. Channel interlacing: A geometric concept for intensification and design of the internal structure of fluid contactors. Chemical Engineering Science 66(4), 709-720. 
1 parallel flow heat exchangers, part II: Modified inlet header. Applied Thermal Engineering 31(16),

$2 \quad 3235-3242$.

3 Wang, L., Fan, Y., Luo, L., 2010. Heuristic optimality criterion algorithm for shape design of fluid flow.

4 Journal of Computational Physics 229(20), 8031-8044.

5 Wang, L., Fan, Y., Luo, L. 2014. Lattice Boltzmann method for shape optimization of fluid distributor.

6 Computers \& Fluids 94, 49-57.

7 Wang, S., Wang, S., 2007. Distribution optimization for plate-fin catalytic combustion heat exchanger.

8 Chemical Engineering Journal 131(1), 171-179.

9 Wen, J., Li, Y., 2004. Study of flow distribution and its improvement on the header of plate-fin heat

10 exchanger. Cryogenics 44(11), 823-831.

11 Wolfram, S., 2002. A new kind of science. Wolfram media ISBN-10: 1579550088.

12 Yue, J., Boichot, R., Luo, L., Gonthier, Y., Chen, G., Yuan, Q., 2010. Flow distribution and mass transfer

13 in a parallel microchannel contactor integrated with constructal distributors. AIChE Journal 56(2),

$14 \quad 298-317$. 


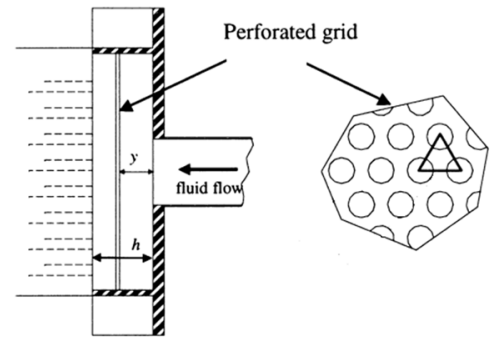

(a)

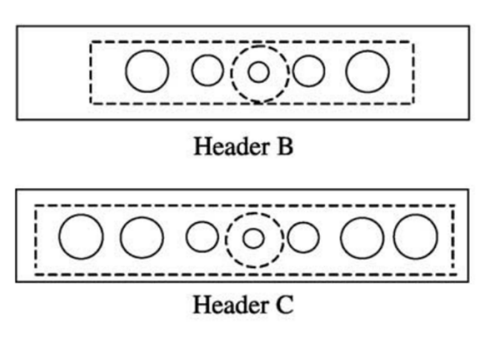

(b)
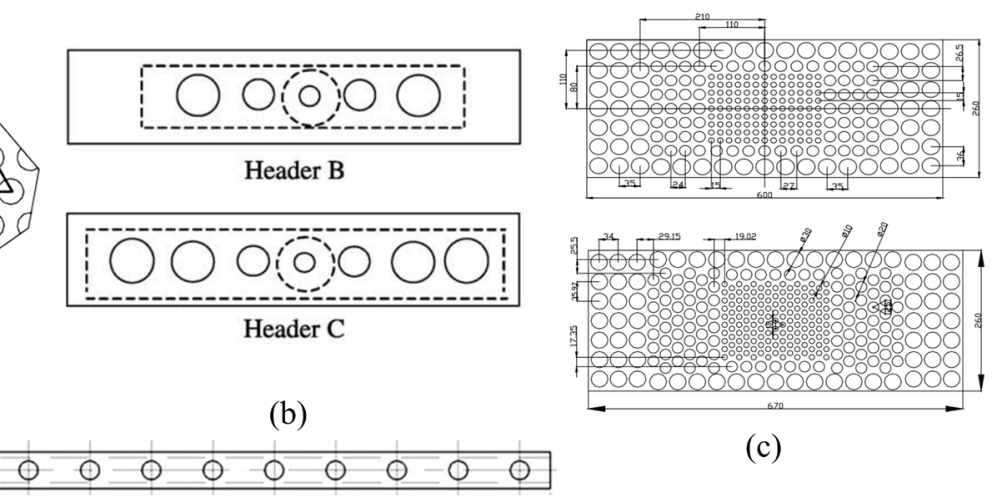

(c)

0000000000000000000000

(e)

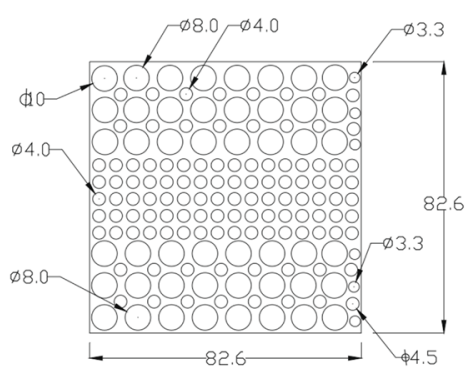

(d)

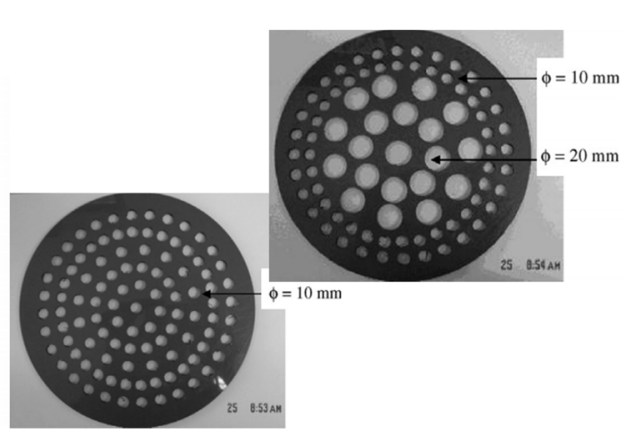

(g)
2

Adapted from Wang et al. (2011). (f) Adapted from Krichnavaruk and Pavasant (2002). (g) Adapted from Maharaj

Fig. 1. Different baffle configurations proposed in the literature. (a) Adapted from Lalot et al. (1999). (b)

Adapted from Jiao et al. (2003b). (c) Adapted from Wen et al. (2006). (d) Adapted from Ismail et al. (2009). (e) et al. (2007). 

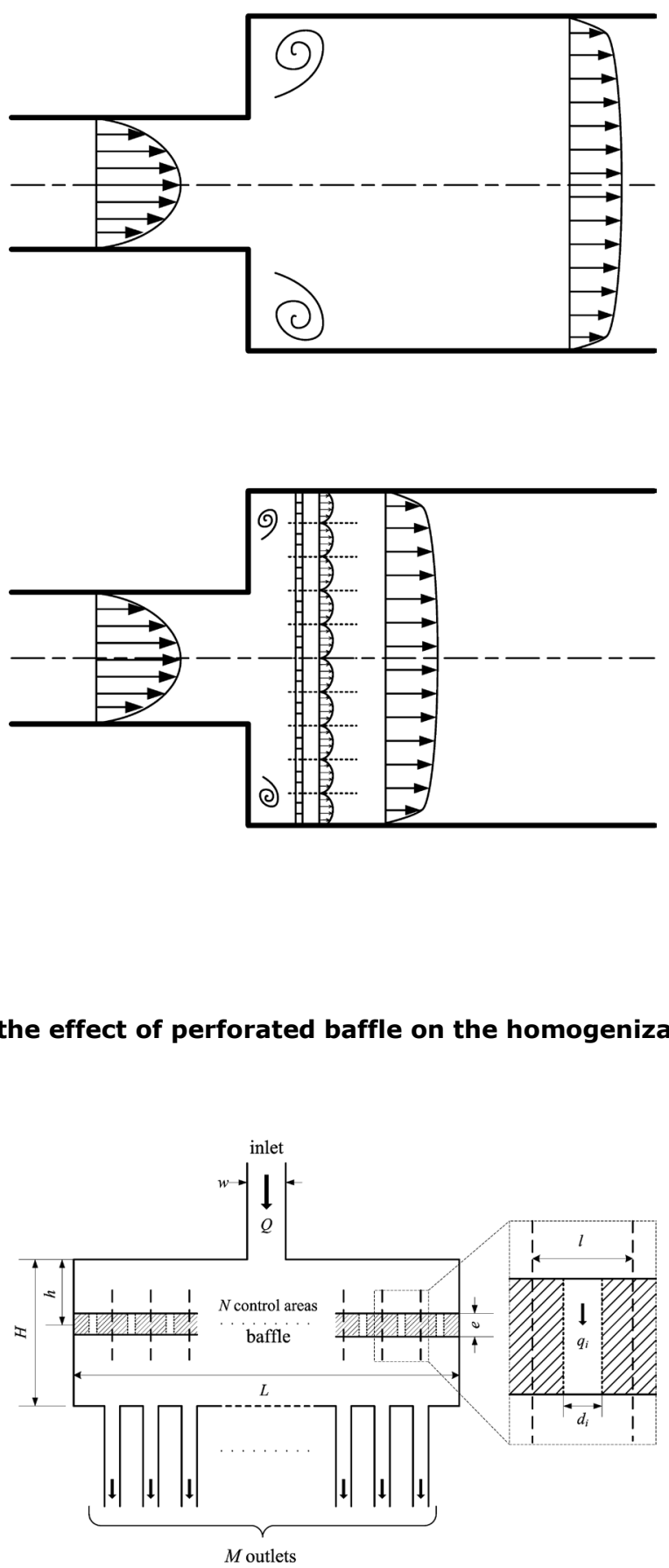

4 Fig. 3. Representative example of a fluid distributor with insertion of perforated baffle. 


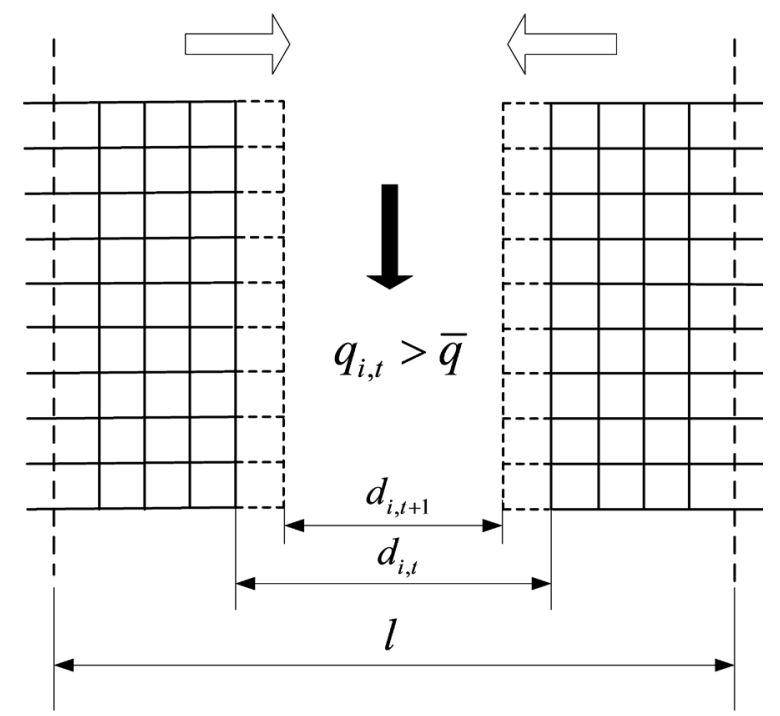

(a)

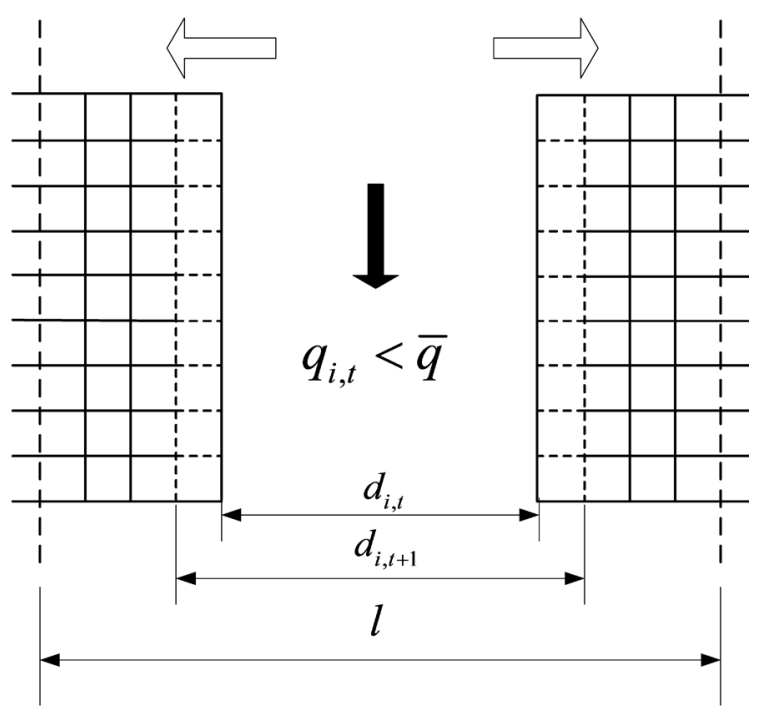

(b)

1

2 Fig. 4. Basic principles of the optimization algorithm. (a) Reduction of the orifice; (b) Enlargement of the 3 orifice 


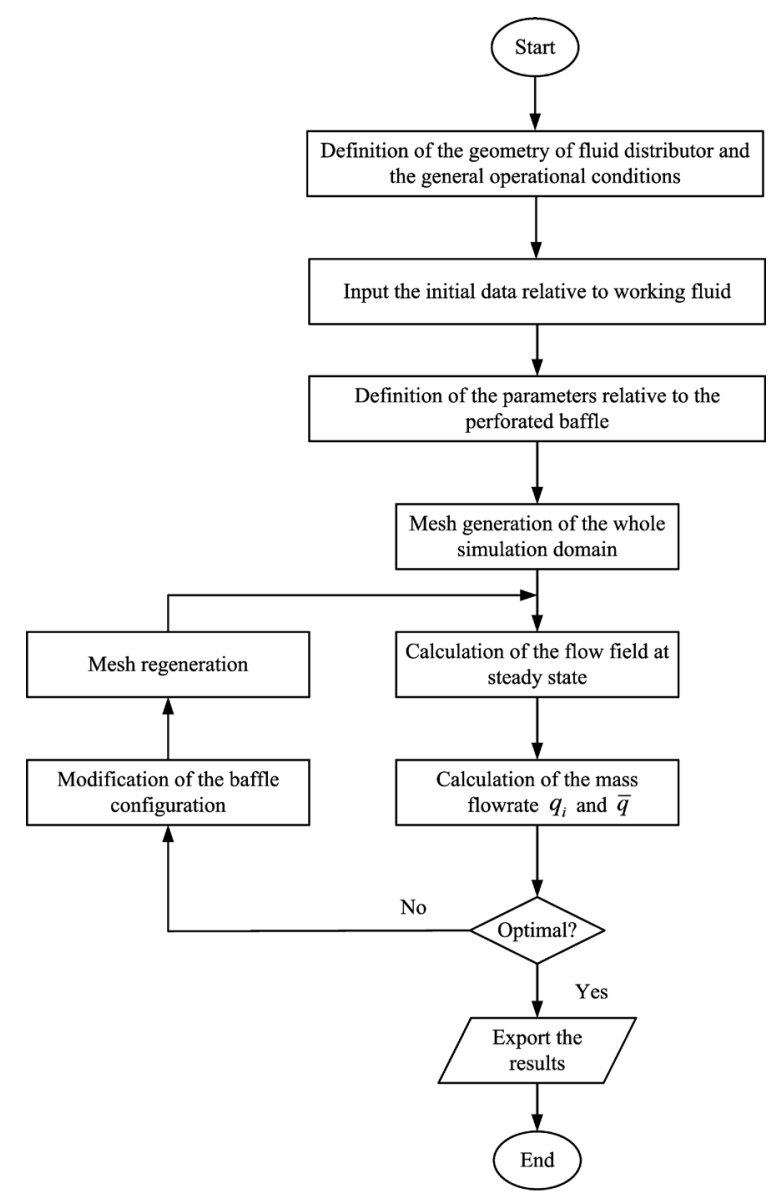

Fig. 5. Flow chart of the algorithm.

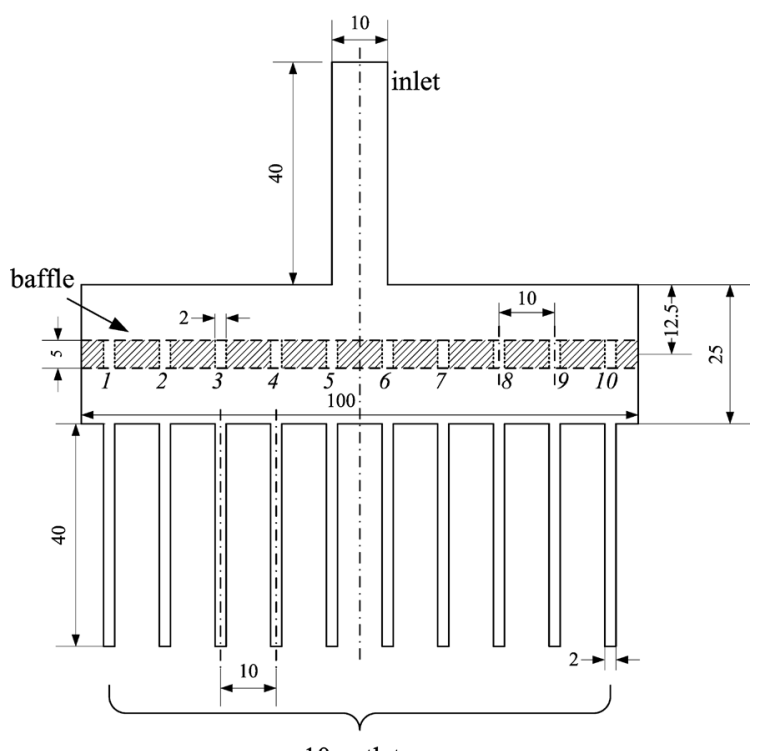

10 outlets 

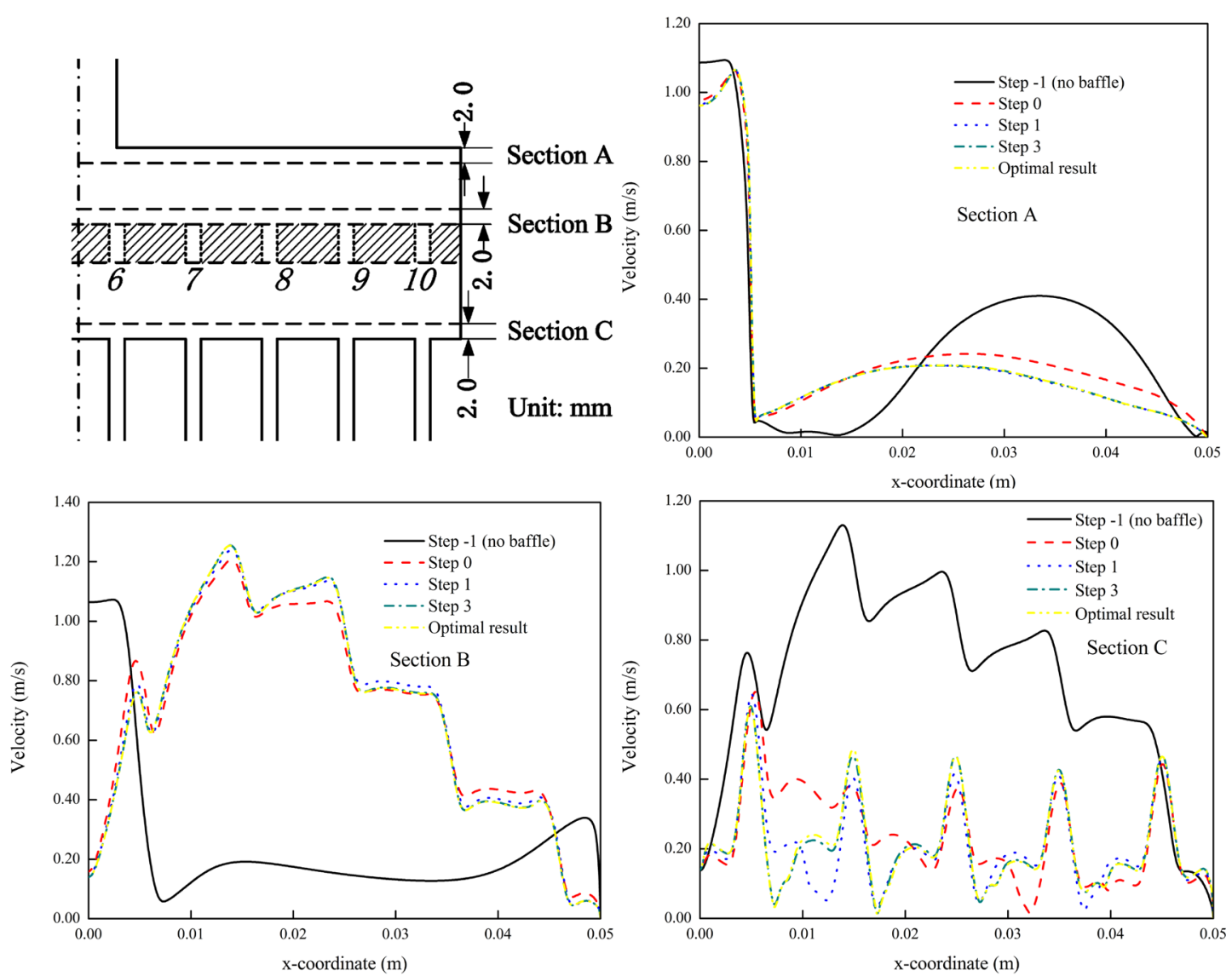

(a)

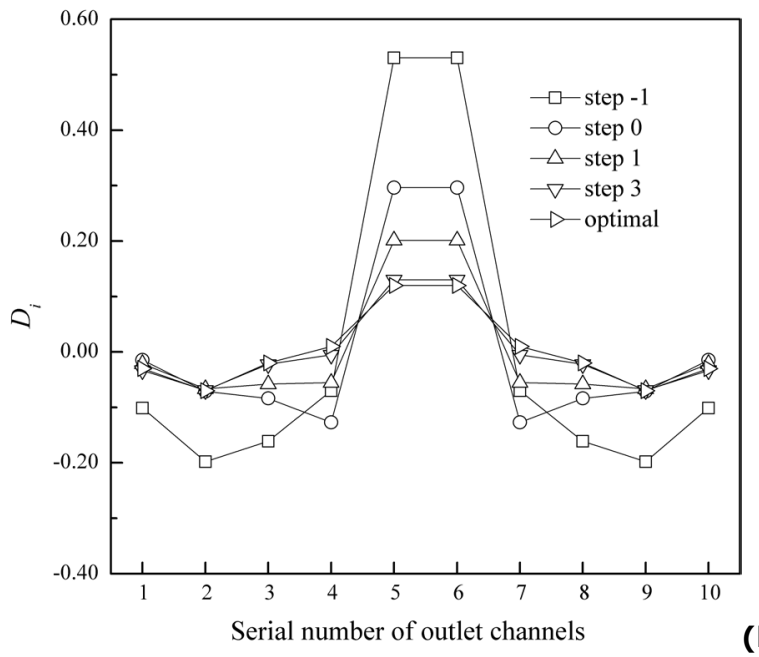

Fig. 7. Shape and flow field evolution of different optimization steps at three sections (a); Relative 

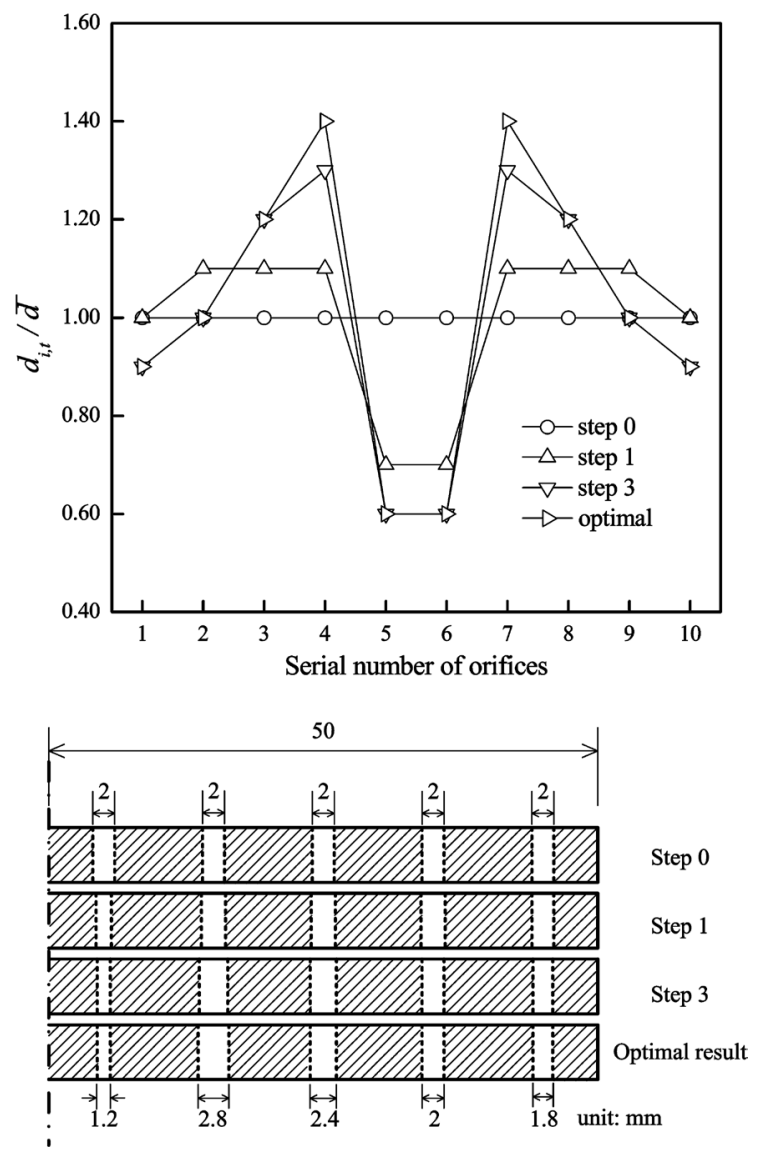

2 Fig. 8. Evolution of size distribution of orifices on the baffle along with optimization steps. $N=10 ; M=10$;

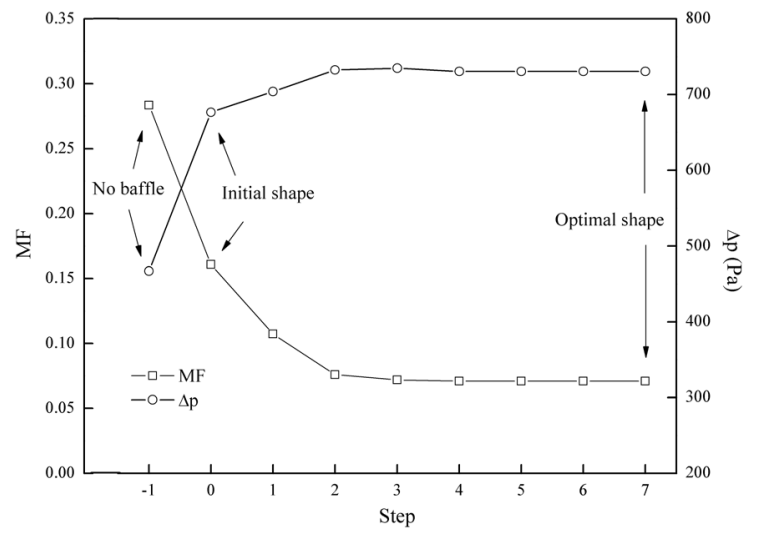

5 Fig. 9. Maldistribution factor (MF) and pressure drop ( $\Delta \mathrm{p})$ as a function of optimization steps. $N=10$; 

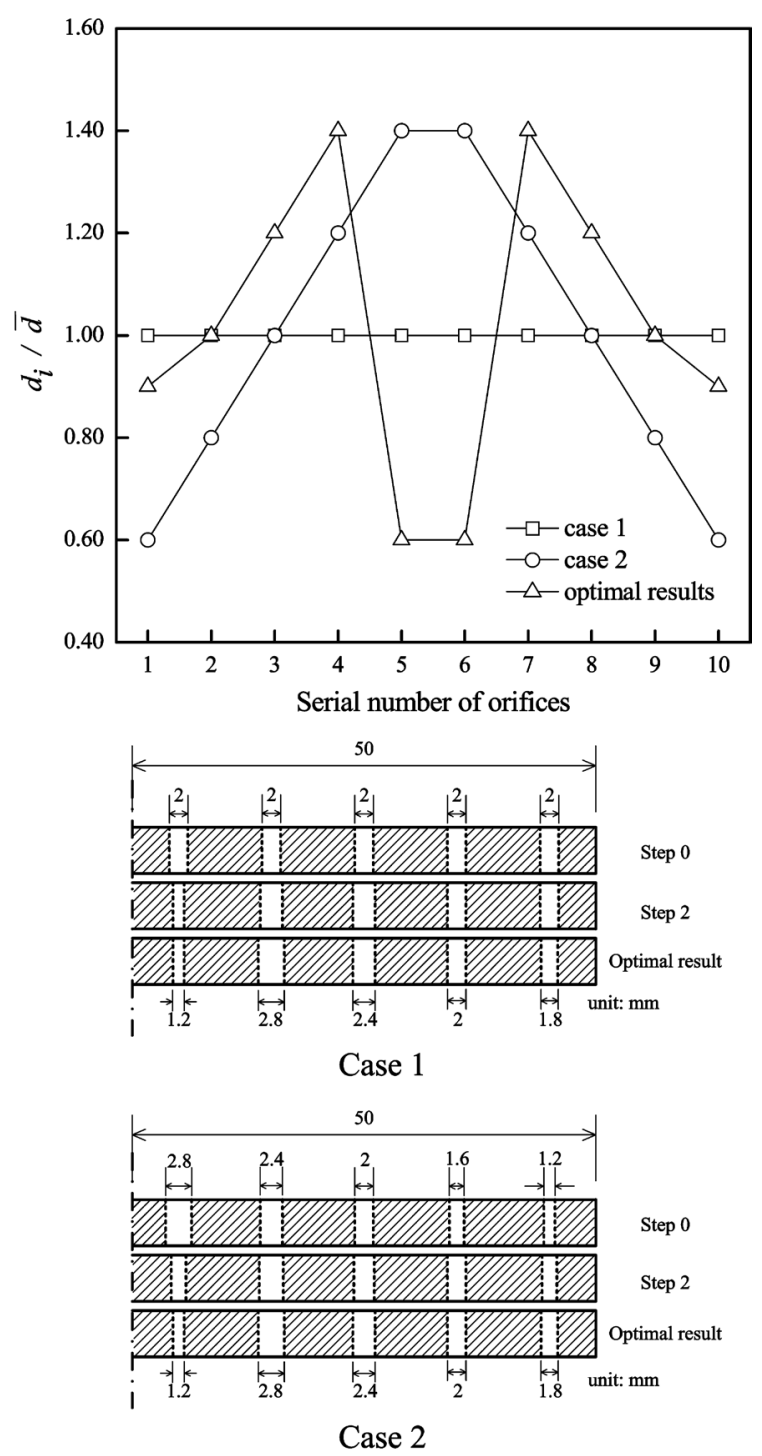

2 Fig. 10. Evolution of size distribution for different initial shapes.

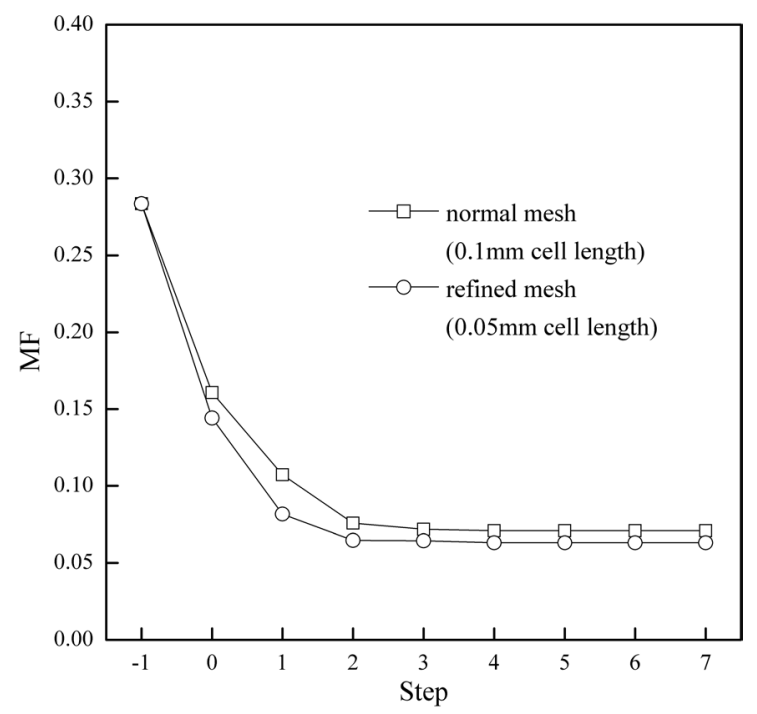


1 Fig. 11. Influence of mesh density on the performance of optimization algorithm.
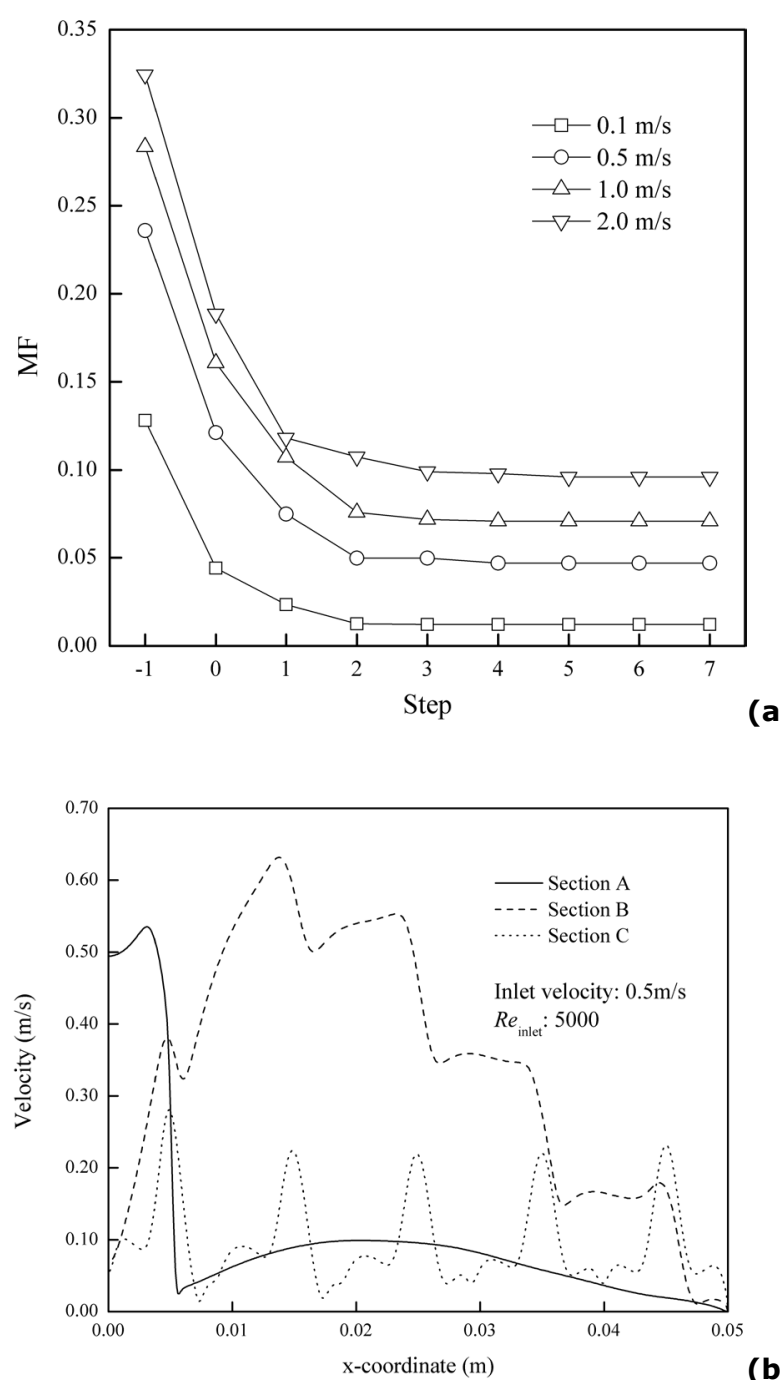

a)

(b)

Fig. 12. Influence of inlet flowrate on the performance of optimization algorithm. $N=10 ; M=10 ; \Phi=20 \%$; 


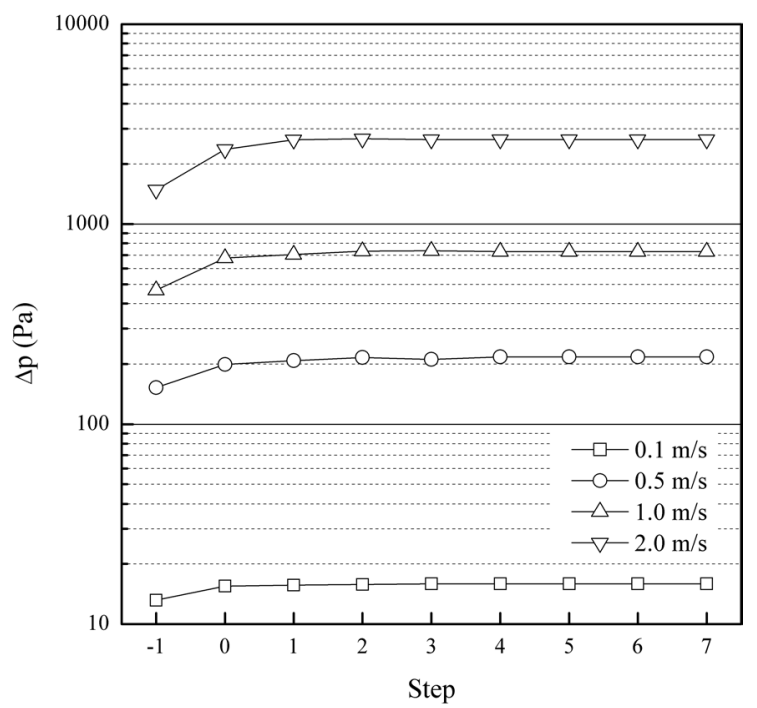

Fig. 13. Influence of inlet flowrate on the pressure drop in the baffled fluid distributor. $N=10 ; M=10$;

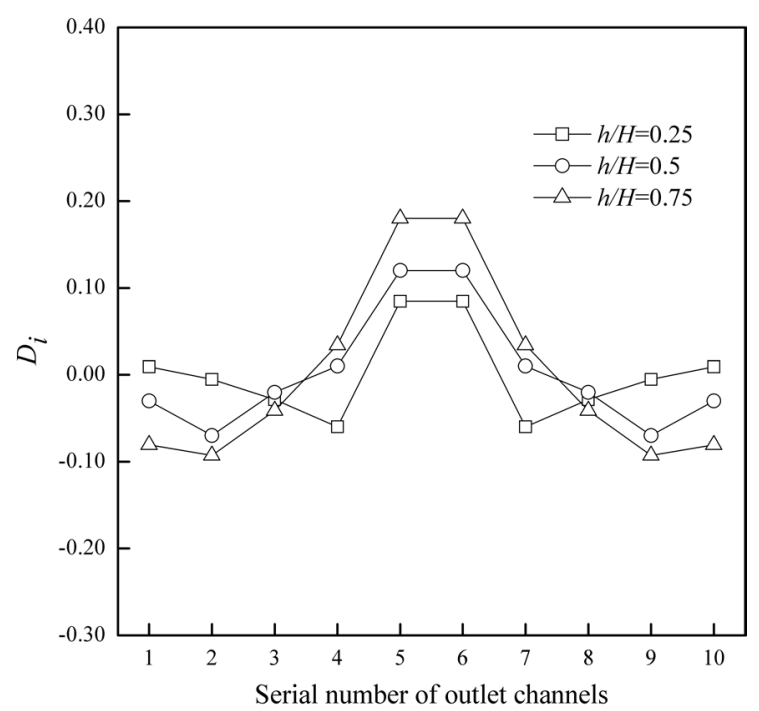

Fig. 14. Relative flowrate deviation for optimized configurations with different baffle locations. $N=10$; 


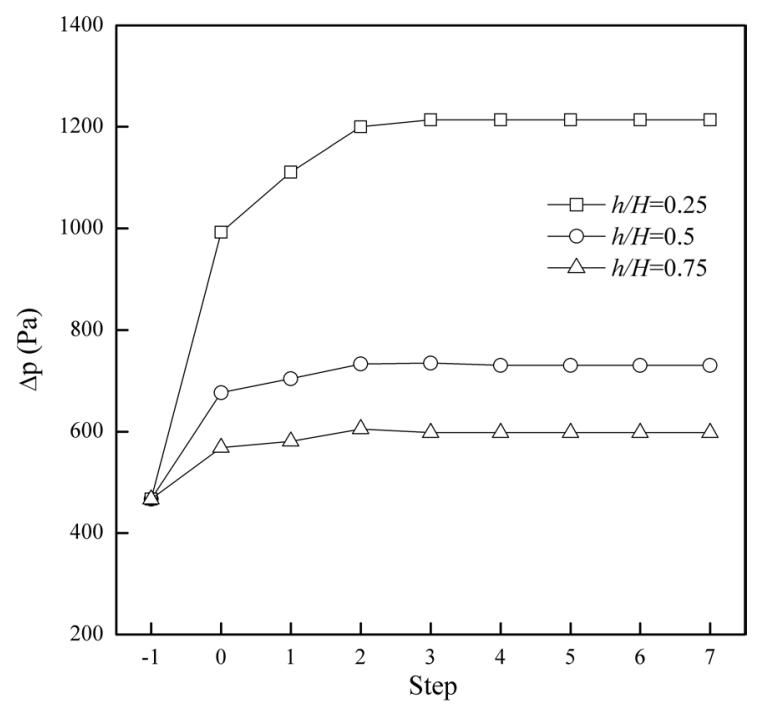

2 Fig. 15. Pressure drop as a function of optimization step, for different baffle locations. $N=10 ; M=10$;

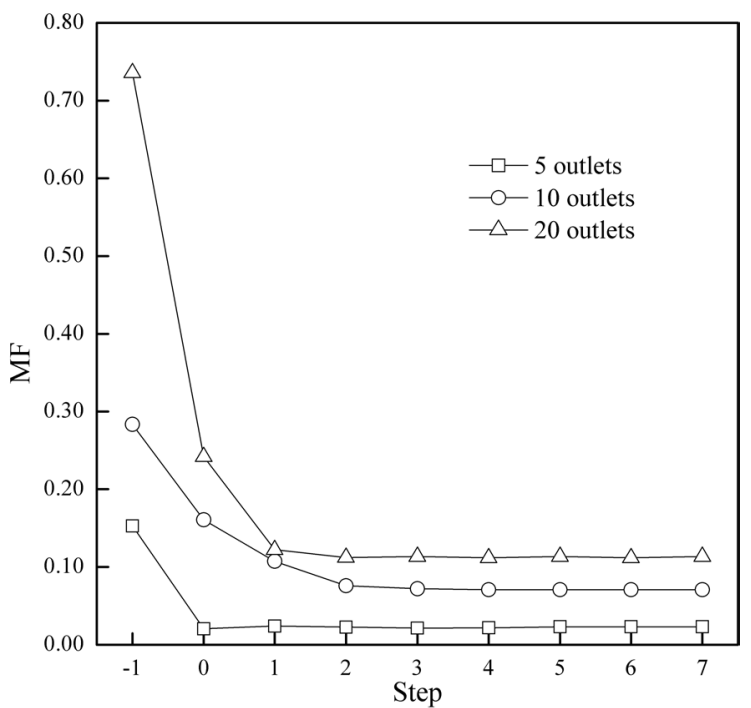
inlet velocity $=1 \mathrm{~m} \cdot \mathrm{s}^{-1}$.

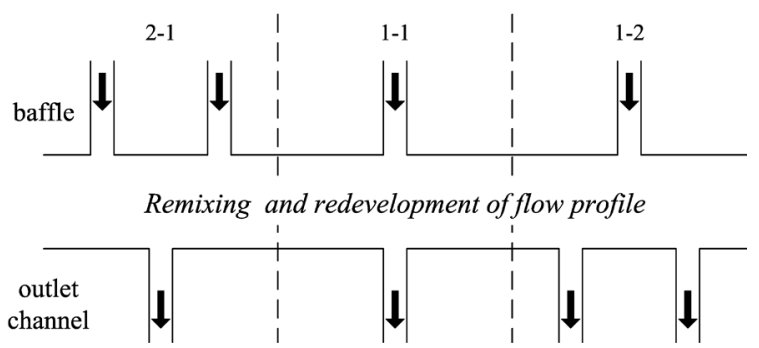


1 Fig. 17. Schematic view of the topological connectedness between the number of orifices and the number of parallel outlet channels.

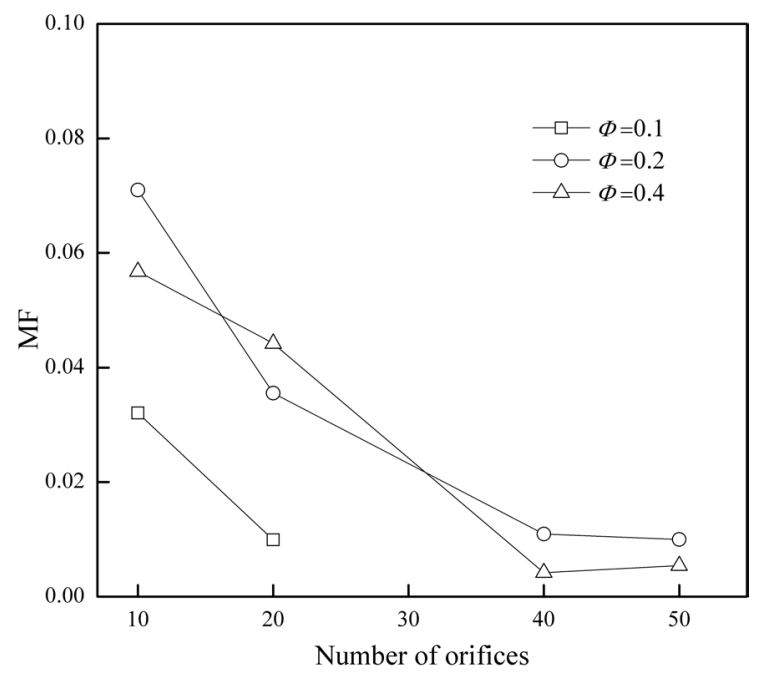

Fig. 18. Influences of global porosity and number of orifices on the optimized flow distribution

uniformity. $M=10 ; h / H=0.5 ;$ inlet velocity $=1 \mathrm{~m} \cdot \mathrm{s}^{-1}$.

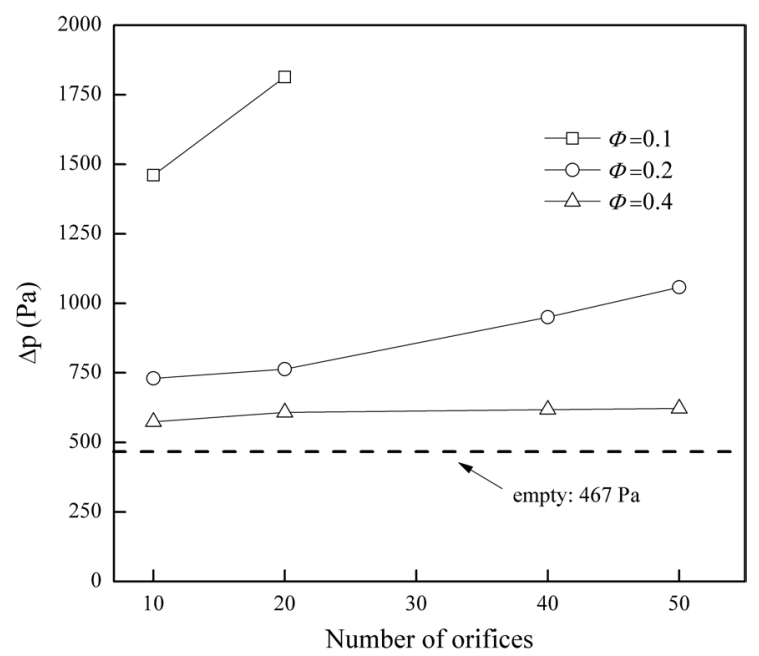

7 Fig. 19. Influences of global porosity and number of orifices on the pressure drop increase. $M=10$;

$h / H=0.5 ;$ inlet velocity $=1 \mathrm{~m} \cdot \mathrm{s}^{-1}$. 


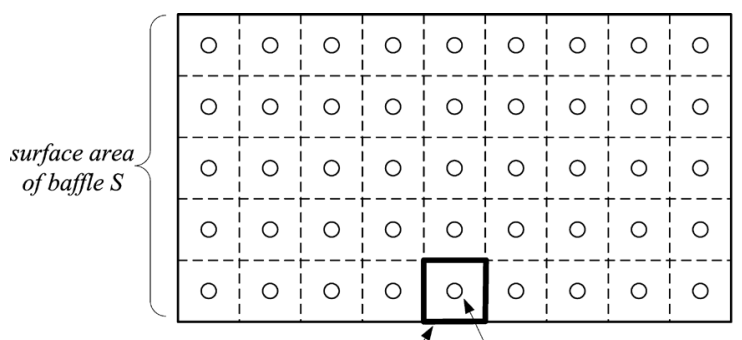

surface area of control size of perforated orifice $a_{i}$ volume $s$

rectangular surface

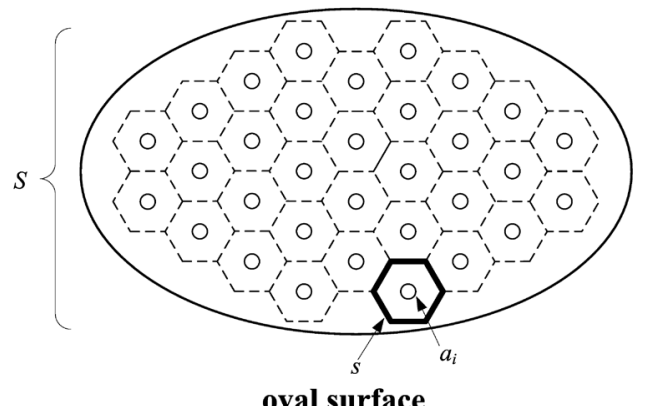

oval surface

2 Fig. 20. Division of a baffle surface by numerous control volumes for 3D application. 
List of tables

2 Table 1. Selected studies on fluid distributor with insertion of perforated baffle.

\begin{tabular}{|c|c|c|c|c|c|c|c|c|}
\hline Study & $\mathbf{N} / \mathbf{E}$ & Device & Geometry & $\begin{array}{l}\text { Working } \\
\text { medium }\end{array}$ & Working conditions & Baffle configuration & $\begin{array}{l}\text { Distribution uniformity } \\
\text { improvement }\end{array}$ & $\begin{array}{c}\text { Global performance } \\
\text { improvement }\end{array}$ \\
\hline $\begin{array}{l}\text { Lalot et al. } \\
\qquad(1999)\end{array}$ & $\mathrm{N}, \mathrm{E}$ & $\begin{array}{c}\text { Heat } \\
\text { exchanger }\end{array}$ & $\begin{array}{c}\text { Inlet tube: Diameter }=60 \mathrm{~mm} \\
\text { Header: } \\
\text { Width=Length= } 233 \mathrm{~mm}, \text { Height }=63 \mathrm{~mm} \\
\text { Number of channel }=128 \\
\text { Diameter of channel }=9.52 \mathrm{~mm}\end{array}$ & Air & $\begin{array}{c}\mathrm{Re}=10000 \\
\text { (mean among channels) }\end{array}$ & $\begin{array}{c}\text { Uniform perforated grid } \\
\text { Orifice diameter: } 4 \mathrm{~mm} \\
\text { Distance between orifices: the side of the } \\
\text { equilateral triangle varies from } 6 \text { to } 9 \mathrm{~mm} \\
\text { (Fig.1(a)) }\end{array}$ & $\begin{array}{l}\text { Flowrate ratio: from } 4 \text { (initial } \\
\text { value) to less than } 1.5\end{array}$ & $\begin{array}{l}\text { No hot spots found; } \\
\text { the power input } \\
\text { increased by } 67 \%\end{array}$ \\
\hline $\begin{array}{l}\text { Jiao et al. } \\
\text { (2003b) }\end{array}$ & $\mathrm{E}$ & $\begin{array}{c}\text { Heat } \\
\text { exchanger }\end{array}$ & $\begin{array}{c}\text { Inlet tube: Diameter }=38 \mathrm{~mm} \\
\text { Header: } \\
\text { Radius }=30 \mathrm{~mm} \text {, Length }=250 \mathrm{~mm} \\
\text { Number of channel=30 (actual } \\
\text { measurement) }\end{array}$ & Water & $\begin{array}{c}\mathrm{Re}=1100 \text { and } 3000 \\
\text { (inlet) }\end{array}$ & $\begin{array}{c}\text { A: no baffle } \\
\text { B: Diameter }=25,20,15,20,25 \mathrm{~mm} \text { (one row) } \\
\text { C: Diameter= } 25,25,20,15,20,25,25 \mathrm{~mm} \text { (one } \\
\text { row) } \\
\text { (Fig.1(b)) }\end{array}$ & $\begin{array}{l}\text { Flowrate ratio: from } 2.08(\mathrm{~A}) \\
\text { to } 1.2(\mathrm{C})(\mathrm{Re}=1100) \\
\text { from } 2.81(\mathrm{~A}) \text { to } 1.4(\mathrm{C}) \\
(\mathrm{Re}=3000)\end{array}$ & Not mentioned \\
\hline $\begin{array}{l}\text { Wen et al. } \\
(2006)\end{array}$ & $\mathrm{N}, \mathrm{E}$ & $\begin{array}{c}\text { Heat } \\
\text { exchanger }\end{array}$ & $\begin{array}{c}\text { Inlet tube: } \\
\text { Diameter }=200 \mathrm{~mm} \text {, Length }=176 \mathrm{~mm} \\
\text { Header: } \text { Radius }=154 \mathrm{~mm}, \text { Length }=905 \mathrm{~mm} \\
\text { Number of channel }=41 \\
\text { Diameter of channel }=9.5 \mathrm{~mm}\end{array}$ & Air & $\mathrm{Re}=60000$ (inlet) & $\begin{array}{l}\text { A: no baffle } \\
\text { B: multi-row, non-uniform, diameter from } 10 \\
\text { to } 30 \mathrm{~mm} \\
\text { C: multi-row, non-uniform, staggered } \\
\text { arrangement, diameter from } 10 \text { to } 30 \mathrm{~mm} \\
\text { (Fig.1(c)) }\end{array}$ & $\begin{array}{c}\text { Flowrate ratio: } 23.225(\mathrm{~A}) \\
2.554(\mathrm{~B}), 1.763(\mathrm{C}) \\
\text { MF: } 1.210(\mathrm{~A}), 0.307(\mathrm{~B}) \\
0.209(\mathrm{C})\end{array}$ & $\begin{array}{l}\text { Heat exchanger } \\
\text { efficiency enhanced } \\
\text { by about } 12 \% \text {; } \\
\text { pressure loss increase } \\
\text { less than } 5 \%\end{array}$ \\
\hline $\begin{array}{l}\text { Ismail et al. } \\
\text { (2009) }\end{array}$ & $\mathrm{N}, \mathrm{E}$ & $\begin{array}{c}\text { Heat } \\
\text { exchanger }\end{array}$ & $\begin{array}{c}\text { Inlet tube: Diameter }=25 \mathrm{~mm} \\
\text { Header: Width }=85 \mathrm{~mm} \\
5 \text { layers for hot flow, } 6 \text { layers for cold flow }\end{array}$ & Air & $\begin{array}{c}\text { Mass flowrate: } \\
0.035 \mathrm{~kg} \cdot \mathrm{s}^{-1} \text { (inlet) }\end{array}$ & $\begin{array}{l}\text { Multi-row, non-uniform, diameter from } 3.34 \text { to } \\
\qquad \begin{array}{c}8 \mathrm{~mm} \\
\text { (Fig.1(d)) }\end{array}\end{array}$ & $\begin{array}{l}\text { To some extent, not } \\
\text { quantified }\end{array}$ & $\begin{array}{l}\text { Total pressure drop } \\
\text { decreased by } 34 \%\end{array}$ \\
\hline $\begin{array}{l}\text { Wang et al. } \\
\text { (2011) }\end{array}$ & $\mathrm{E}$ & $\begin{array}{c}\text { Heat } \\
\text { exchanger }\end{array}$ & $\begin{array}{c}\text { Inlet tube: Diameter }=4 \mathrm{~mm} \\
\text { Header: } \\
\text { Width=Height }=9 \mathrm{~mm}, \text { Length }=90 \mathrm{~mm} \\
\text { Number of channel }=9 \\
\text { Length of channel }=400 \mathrm{~mm} \\
\text { Diameter of channel }=3 \mathrm{~mm}\end{array}$ & Water & $\begin{array}{l}\text { Volume flowrate: } \\
0.5-4 \mathrm{~L} \cdot \mathrm{min}^{-1} \text { (inlet) }\end{array}$ & $\begin{array}{l}\text { Uniform and non-uniform, one row } \\
\text { Diameter }=1.2-4 \mathrm{~mm} \\
\text { Number of orifice }=9-28 \\
\text { (Fig. } 1(\mathrm{e}))\end{array}$ & $\begin{array}{l}\text { The best non-uniformity } \\
\text { reached } 0.0017 \text { (Volumn flow } \\
\left.\text { rate }=0.5 \mathrm{~L} \cdot \mathrm{min}^{-1}\right)\end{array}$ & $\begin{array}{c}\text { No vortex flow; } \\
\text { the pressure drop } \\
\text { increased by less than } \\
3 \%\end{array}$ \\
\hline Krichnavar & E & Airlift & Column & Air & Inlet velocity: & Uniform; Diameter $=3-5 \mathrm{~mm}$ & Not mentioned & Overall volumetric \\
\hline
\end{tabular}




\begin{tabular}{|c|c|c|c|c|c|c|c|c|}
\hline $\begin{array}{l}\text { uk and } \\
\text { Pavasant } \\
(2002)\end{array}$ & & contactor & $\begin{array}{c}\text { Height }=2400 \mathrm{~mm} \\
\text { Diameter }=110 \mathrm{~mm}\end{array}$ & & $1.8-8.4 \mathrm{~cm} \cdot \mathrm{s}^{-1}$ & $\begin{array}{l}\text { Number of orifices }=13-37 \\
\text { (Fig. } 1(\mathrm{f}))\end{array}$ & & $\begin{array}{c}\text { mass transfer } \\
\text { coefficient doubled }\end{array}$ \\
\hline $\begin{array}{l}\text { Maharaj et } \\
\text { al. (2007) }\end{array}$ & $\mathrm{N}, \mathrm{E}$ & $\begin{array}{l}\text { Teetered } \\
\text { bed } \\
\text { separator }\end{array}$ & $\begin{array}{c}\text { Column } \\
\text { Height }=1250 \mathrm{~mm} \\
\text { Diameter }=200 \mathrm{~mm}\end{array}$ & Water & $\begin{array}{l}\text { Inlet volume flowrate: } \\
\begin{array}{l}3 \mathrm{~L} \cdot \mathrm{min}^{-1}(\mathrm{~A}) \\
6 \mathrm{~L} \cdot \mathrm{min}^{-1}(\mathrm{~B}) \\
8 \mathrm{~L} \cdot \mathrm{min}^{-1}(\mathrm{C})\end{array}\end{array}$ & $\begin{array}{l}\text { Uniform and non-uniform, } \\
\text { Diameter }=5-29 \mathrm{~mm} \\
\text { Number of orifices }=17-296 \\
\text { (Fig. } 1(\mathrm{~g}) \text { ) }\end{array}$ & $\begin{array}{l}\text { Flowrate ratio: } \\
\text { from } 13.0 \text { to } 2.0(\mathrm{~A}) \\
\text { from } 10.5 \text { to } 1.6(\mathrm{~B}) \\
\text { from } 20.5 \text { to } 2.1(\mathrm{C})\end{array}$ & $\begin{array}{l}\text { Ecart probable }(E p) \\
\text { reduced by } 45 \%-70 \%\end{array}$ \\
\hline $\begin{array}{l}\text { Ong et al. } \\
(2009)\end{array}$ & E & $\begin{array}{l}\text { Bubble } \\
\text { column }\end{array}$ & $\begin{array}{c}\text { Column } \\
\text { Height }=2500 \mathrm{~mm} \\
\text { Diameter }=162 \mathrm{~mm}\end{array}$ & Air & $\begin{array}{l}\text { Inlet velocity: } \\
2-30 \mathrm{~cm} \cdot \mathrm{s}^{-1}\end{array}$ & $\begin{array}{c}\text { Circular and equilateral distribution } \\
\text { Diameter }=0.4-5.1 \mathrm{~mm} \\
\text { Number of orifices }=1-163\end{array}$ & Not mentioned & $\begin{array}{l}\text { The perforated plate } \\
\text { sparger produces a } \\
\text { higher gas holdup }\end{array}$ \\
\hline
\end{tabular}


1 Table 2. Control parameters for different tested cases.

\begin{tabular}{ccccccc}
\hline Case & $\begin{array}{c}\text { Global porosity } \\
\boldsymbol{\Phi}(-)\end{array}$ & $\begin{array}{c}\text { Number of orifices } \\
\boldsymbol{N}(-)\end{array}$ & $\begin{array}{c}\text { Initial size of orifices } \\
\boldsymbol{d}_{\boldsymbol{i}, \boldsymbol{0}}(\mathbf{m m})\end{array}$ & $\begin{array}{c}\text { Number of outlets } \\
\boldsymbol{M}(\boldsymbol{-})\end{array}$ & $\begin{array}{c}\text { Inlet velocity } \\
\left(\mathbf{m} \cdot \mathbf{s}^{-1}\right)\end{array}$ & $\begin{array}{c}\text { Baffle location } \\
\boldsymbol{h} / \boldsymbol{H}\end{array}$ \\
\hline 1 & $10 \%$ & 10 & 1 & & \\
2 & $10 \%$ & 20 & 0.5 & & \\
3 & $20 \%$ & 10 & 2 & & \\
4 & $20 \%$ & 20 & 1 & & \\
5 & $20 \%$ & 40 & 0.5 & & \\
6 & $20 \%$ & 50 & 0.4 & & \\
7 & $40 \%$ & 10 & 4 & & \\
8 & $40 \%$ & 20 & 2 & & \\
9 & $40 \%$ & 40 & 1 & & \\
10 & $40 \%$ & 50 & 0.8 & & \\
\hline
\end{tabular}

2 